Article

\title{
An Experimental and Numerical Study on the Flexural Performance of Over-Reinforced Concrete Beam Strengthening with Bolted-Compression Steel Plates: Part II
}

\author{
Shatha Alasadi $1,2, *(1)$, Zainah Ibrahim ${ }^{1, *}$, Payam Shafigh ${ }^{3,4, *}$, Ahad Javanmardi ${ }^{5}$ (i) \\ and Karim Nouri ${ }^{1}$ \\ 1 Department of Civil Engineering, Faculty of Engineering, University of Malaya, Kuala Lumpur 50603, \\ Malaysia; k.nouri@siswa.um.edu.my \\ 2 Department of Civil Engineering, College of Engineering, Al-Mustansiriyah University, P.O. Box, \\ Baghdad 46049, Iraq \\ 3 Department of Building Surveying, Faculty of Built Environment, University of Malaya, \\ Kuala Lumpur 50603, Malaysia \\ 4 Centre for Building, Construction and Tropical Architecture (BuCTA), Faculty of Built Environment, \\ University of Malaya, Kuala Lumpur 50603, Malaysia \\ 5 College of Civil Engineering, Fuzhou University, 2 Xueyuan Road, University Town, Fuzhou 35018, China; \\ ahadjavanmardi@gmail.com \\ * Correspondence: shsk_alasadi@yahoo.com or shatha@uomustansiriyah.edu.iq (S.A.); \\ zainah@um.edu.my (Z.I.); pshafigh@gmail.com or pshafigh@um.edu.my (P.S.)
}

Received: 22 October 2019; Accepted: 12 December 2019; Published: 20 December 2019

Featured Application: A bolt-compression steel plate (BCSP) system is usually used for strengthening the flexural performance and improving the failure mode of over-reinforced beams and may easily be employed in normal design applications. This method is applicable for protecting sections against further deterioration and for strengthening. This method provides an economical solution for the retrofitting or rehabilitation of structures, regardless of their elements.

\begin{abstract}
This study presents an experimental investigation and finite element modelling (FEM) of the behavior of over-reinforced simply-supported beams developed under compression with a bolt-compression steel plate (BCSP) system. This study aims to avoid brittle failure in the compression zone by improving the strength, strain, and energy absorption (EA) of the over-reinforced beam. The experimental program consists of a control beam (CB) and three BCSP beams. With a fixed steel plate length of $1100 \mathrm{~mm}$, the thicknesses of the steel plates vary at the top section. The adopted plate thicknesses were $6 \mathrm{~mm}, 10 \mathrm{~mm}$, and $15 \mathrm{~mm}$, denoted as BCSP-6, BCSP-10, and BCSP-15, respectively. The bolt arrangement was used to implement the bonding behavior between the concrete and the steel plate when casting. These plates were tested under flexural-static loading (four-point bending). The load-deflection and EA of the beams were determined experimentally. It was observed that the load capacity of the BCSP beams was improved by an increase in plate thickness. The increase in load capacity ranged from $73.7 \%$ to $149 \%$ of the load capacity of the control beam. The EA was improved up to about $247.5 \%$ in comparison with the control beam. There was also an improvement in the crack patterns and failure modes. It was concluded that the developed system has a great effect on the parameters studied. Moreover, the prediction of the concrete failure characteristics by the FE models, using the ABAQUS software package, was comparable with the values determined via the experimental procedures. Hence, the FE models were proven to accurately predict the concrete failure characteristics.
\end{abstract}


Keywords: ABAQUS; over-reinforced concrete; steel plate; FEM; bolting; BCSP

\section{Introduction}

The use of an externally bolted/glued steel plate system has been proven to be an effective technique for strengthening/repairing reinforced concrete (RC) structures. This method of strengthening is low-cost and efficient for improving both flexural and shear strength. It is also known to have high stiffness. In general, the plates are bonded/glued to the beams and attached at the compression and tension zones of the RC beams to provide a locking mechanism that will increase the load-bearing capacity and ductility of the section in order to avoid brittle failure [1-15].

In the past two decades, many attempts have been made to comprehensively understand and apply steel plate systems. Most of these studies have focused on the flexural performance of bolted steel plates (BSP) on the side faces of the beams. A study by Oehlers et al [5]. revealed that there is a partial interaction between the bolted steel plates and the RC beams. Analytical models were established for the flexural behavior of the BSP beams. It was found that there is a relationship between the longitudinal and transverse interactions of the steel plates. This relationship was derived using the identical curvatures of both steel plates [8]. Ignoring the effects of this partial interaction in theoretical computations can lead to an overestimation of the flexural performance enhancement achieved by BSP. This overestimation can be as much as 30\%, as reported by Siu and Su [10]. Li et al. [11] proposed a simplified "two factor and three steps" design method for flexural strengthening. This method was based on the combined influence of the stiffness ratio and the shear stiffness of the anchor bolts on the relative slips. However, the strengthening/repair of structural $\mathrm{RC}$ beams with various techniques and materials has been widely studied in recent decades.

Brittle compression failure can be avoided by using proper confinement. Few studies have been done on the confinement of concrete at the compression zone in a beam. This is one of the most important methods to develop a flexural over-reinforced section by using one or two helical reinforcements with a medial span in the compression zone $[16,17]$. However, the confined compression zone in beams has been developed recently based on some studies conducted on the confinement of columns $[18,19]$. Based on this, further investigation is needed on the behavior of confined normal strength concrete (NSC), high strength concrete (HSC), and pre-stressed beams [20,21]. Also, few studies have reviewed and reported on the installation of short stirrup confinement in the compression zone [22,23]. Moreover, there are studies on the improvement of beam capacity using a system consisting of two or three layers, referred to as a hybrid system. This type of system depends on the use of different types of materials, which include HSC and light weight concrete (LWC) with steel fibres (SF) [24], and is also influenced by the strength of the materials, such as normal reinforcement (NR) and Fiber Reinforced Polymer (FRP) bars $[25,26]$. To enhance the strength, stiffness, and ductility properties of concrete, the use of proper confinement is necessary to restrain lateral expansion and avoid brittle failure $[16,17,27]$.

In contrast, the design of the flexural beam in the case of the brittle failure of concrete is not permitted by several international codes of practice because the member has less ductility $[28,29]$. The reinforcement ratio of flexural RC beams is classified into three categories, namely, under, balance, and over, according to ACI 318-02 [28,29]. Therefore, the development of flexural over and under RC beams can be achieved by replacing existing materials with higher quality materials that have better performance or through the addition of a structurally enhanced section with additional load-bearing materials, such as adding helical reinforced, short stirrups and bolted steel plates to the sides of RC beams. The flexural over RC beam section, with additional load-bearing materials, is connected to the compression surface of the structural member, and, therefore, it enhances the ductility and strength of the section and reduces the crushing failure of the concrete section. 
One of the main advantages of confinement is the possibility of using a steel ratio higher than the balance. This can be less expensive than conventional methods. This calls for more research in this area, in order to develop more techniques for concrete confinement and un-confinement. More work is also needed towards investigating the other critical practical dimensions of flexural failures in over-reinforced beams. Therefore, this study aims to investigate the behavior of simply-supported steel plates on over-reinforced beams under four-point loading, in comparison with the strength of an unconventional bolt-compression steel plate (BCSP) system adopting different thicknesses of steel plates. The failure modes, load-carrying capacities, energy absorption capacities, and strains of the tested specimens are presented and discussed in detail. Moreover, finite element (FE) models have been developed and analyzed using the ABAQUS software package [30].

BCSP beams with normal structures appear to be more cost-effective for high rise buildings. Projects like these are quite expensive, with a very high life expectancy. The economic advantage of using bolted steel plates in the compression zone of an over-reinforced concrete beam are derived from the use of a lesser amount of reinforcements. This offers a reduction of the reinforcement ratio of the beams when compared with traditional designs based on code requirements, while still achieving an increase in flexural strength and stiffness with acceptable ductility [28,29]. In addition, improving the mode of failure of the over-reinforced beams will further increase efficiency. These are very necessary developments for the critical zone in the beam section. For RC beams, improving the flexural and compressive strength of the beam, as well as achieving a ductile and inelastic mechanism with a suitable deformation capacity, will reduce crushing when using bolt-compression steel plate systems.

\section{Experimental Work}

\subsection{Specimen Details and Testing Setup}

Four-point bending was applied to four full scales of simply-supported over-beams, which were fabricated and tested in the laboratory. All of the specimens have the same geometrical dimensions, as shown in Table 1 and Figure 1. The lengths, widths, and depths of the RC beams were 2400, 200 and $300 \mathrm{~mm}$, respectively. The length of the shear span was $700 \mathrm{~mm}$, and the shear-effective depth ratio was about $2.7(\mathrm{a} / \mathrm{d}>2.5)$.

The specimens were over-reinforced with $5 \varnothing 20$ tension bars. This represents a steel percentage of $3.27 \%$. The provided shear reinforcement consisted of a transverse reinforcement of $17 \varnothing 6$ and stirrups spaced center to center to the load points at the web shear at $50 \mathrm{~mm}$, which was considered to be adequate for the avoidance of premature shear failure. The yield strength of the steel reinforcement that was adopted in [31]. To ensure that there was no further confinement provided by the stirrups, the middle zone between the load points was not provided with the stirrups. The longitudinal and transverse reinforcement was considered sufficient enough to ensure that the specimens would fail due to flexural compression in both undeveloped and developed cases. This is desirable for achieving the objective of this research, which is to investigate the over-reinforced responses of beams. Here, the control beam (CB) specimen was used to demonstrate the structural performance of an over-reinforced beam prior to development. Three developed specimens were fabricated. The bolt-plate arrangements of these specimens were carefully selected so that the behaviors of the beams remained identical. Thus, the BCSP-6, BCSP-10, and BCSP-15 beam series were developed with 6, 10, and $15 \mathrm{~mm}$ steel plates thicknesses, respectively. The tested steel plates were adopted in this study [32], using 24 bolts to bond the steel plates to the concrete. The size of the steel plate used was $1100 \mathrm{~mm}$ in length by $180 \mathrm{~mm}$ in width, and the bolt was $12 \mathrm{~mm}$ in diameter and $200 \mathrm{~mm}$ in length. The clearance of the holes on the plates was $12.5 \mathrm{~mm}$ [33], which was used for all of the beams, as shown in Table 1 and Figures 2 and 3 .

In the final casting, the steel formwork was used for all the beams, as shown in Figure 3. However, for the BCSP beams of the bolt-compression plates, two pieces of wood were placed under the plates in the process of concrete casting. After curing, the external plates were fixed to the cast-in sockets, 
with bolt clearance holes on the plates, which were provided to facilitate the location of tolerances. The bolts were then coasted to the beam in order to prevent any slippage within the clearance holes of the plates, and additionally to avoid the buckling of the steel plate.

Mixed design proportions of the concrete were used to acquire adequate compressive strength, which was $36.8 \mathrm{MPa}$. After curing for 28 days, as shown in Table 2, ten specimens were cast as concrete cubes $(100 \times 100) \mathrm{mm}$, and additionally a concrete cylinder $(200 \times 100) \mathrm{mm}$, for compressive and tensile strength testing, according to part 1 of B.S., 1997, and BS8110, 1986 [34,35].

All the simply-supported over-reinforced concrete beams were tested under four-point bending over a span of $800 \mathrm{~mm}$. A constant shear span to an effective depth was adopted for all tests. A MTS universal testing machine with a $4000 \mathrm{kN}$ capacity and a $50 \mathrm{~mm}$ stork length was used to apply the static load. The load was transferred from the actuator to the spreader beam using a stub column that was $2000 \mathrm{~mm}$ in height. Figure 4 shows the experimental testing setup for one of the beam specimens. The dimensions and equipment used are also presented in Figures 1 and 2. Two electrical resistance strain gauges were attached at the top of the beams, directly underneath the position of the load cell, in order to measure the concrete strain. Additionally, the two strain gauges on top of the steel plate at the middle were used to measure the strain here. Two strain gauges were attached at the middle of the beam span in the longitudinal direction of the tensile bars on the bottom to measure the tensile strain. A linear variable displacement transducer (LVDT) was used to measure the displacement of the mid-span at a rate of $2 \mathrm{~mm} / \mathrm{min}$ until failure. Based on visual inspection, the point of crack initiation was identified. The propagation of the cracks was also monitored and recorded. The loads that initiated the cracks were recorded. The data were recorded automatically by the data logger.

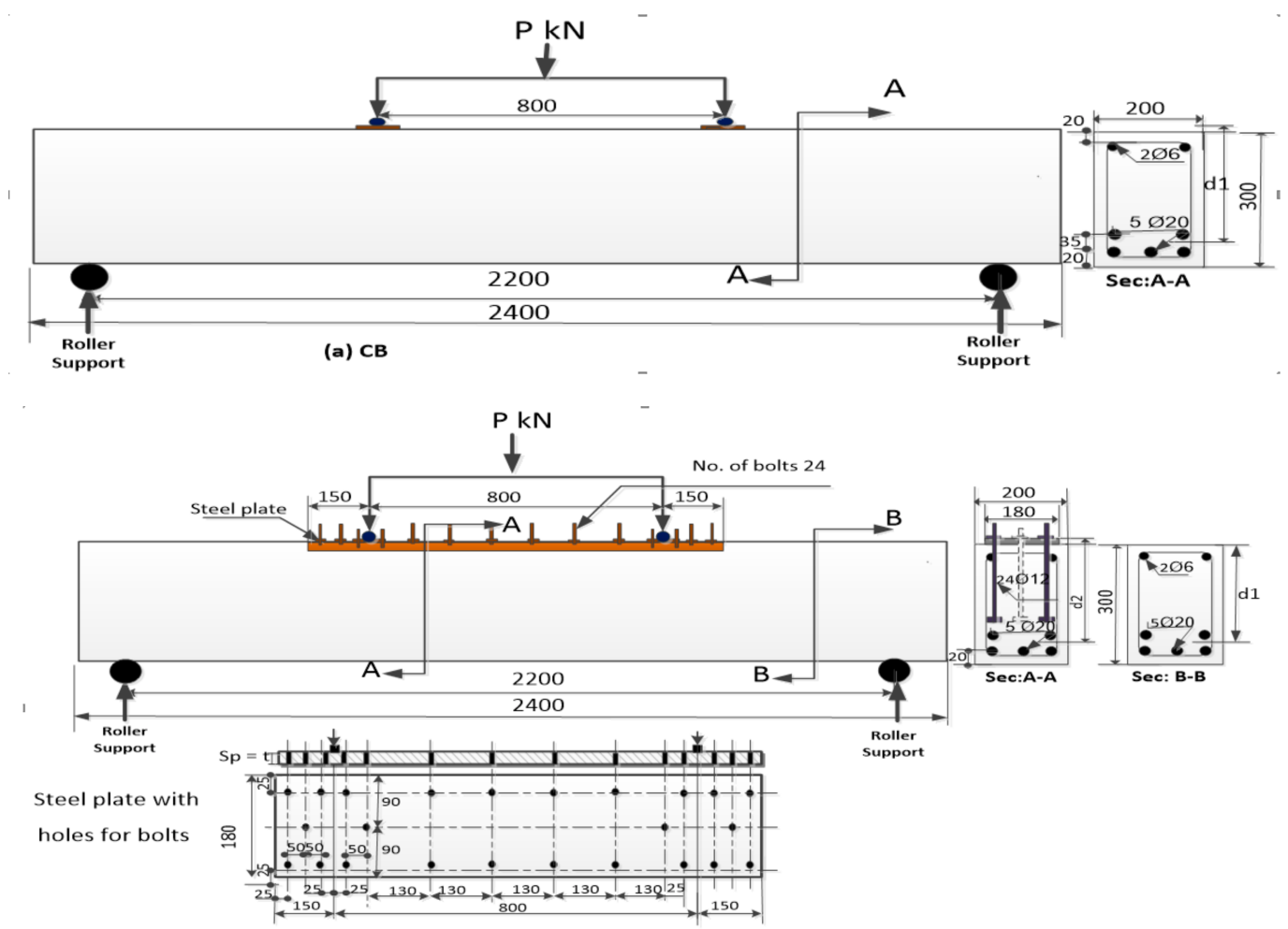

(b) BCSP-6, BCSP-10 \& BCSP-15

Figure 1. Dimension details of all the specimens: (a) The CB and (b) the BCSP-6, BCSP-10, \& BCSP-15 beams (all dimensions are in $\mathrm{mm}$ ). BCSP: Bolt-compression steel plate. CB: Control beam. 

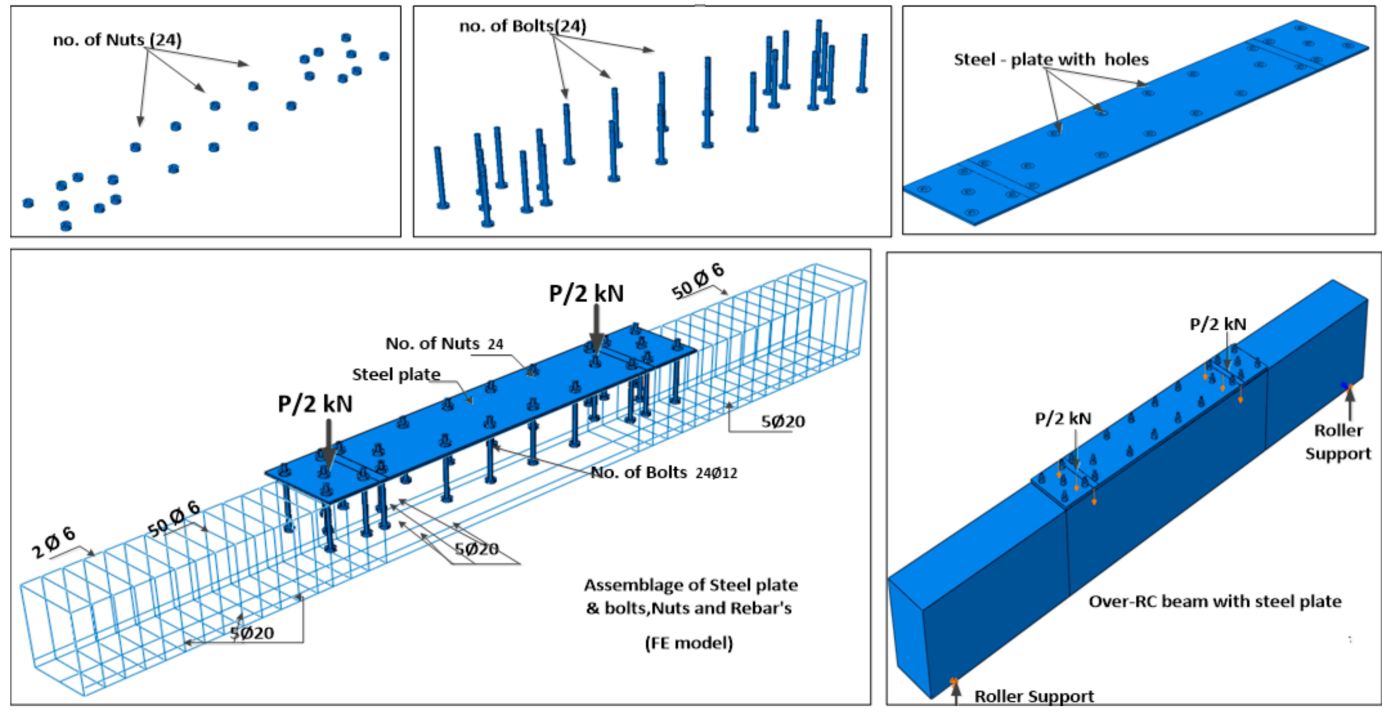

Figure 2. Details of the reinforcement of all the over-reinforced specimens. Over-RC: Overreinforced concrete.
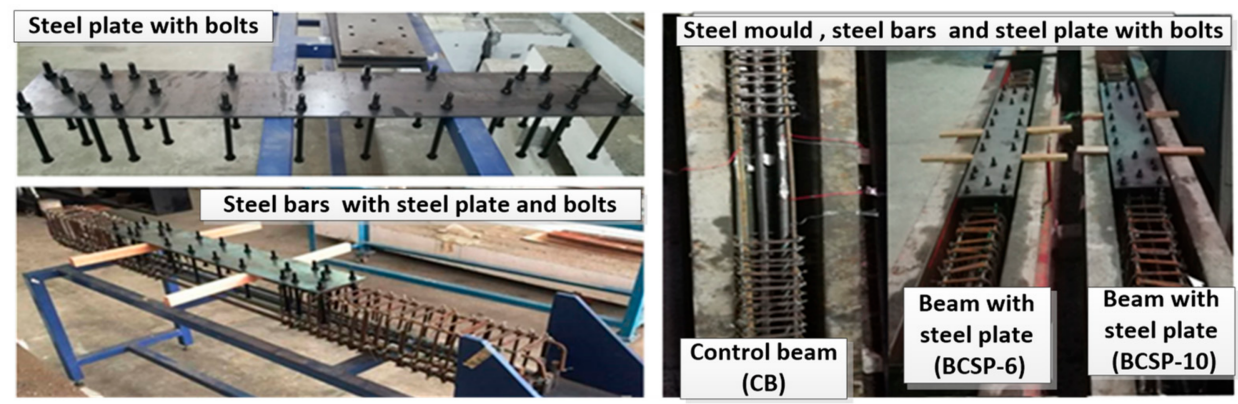

Figure 3. Reinforcement and location of the steel plate.

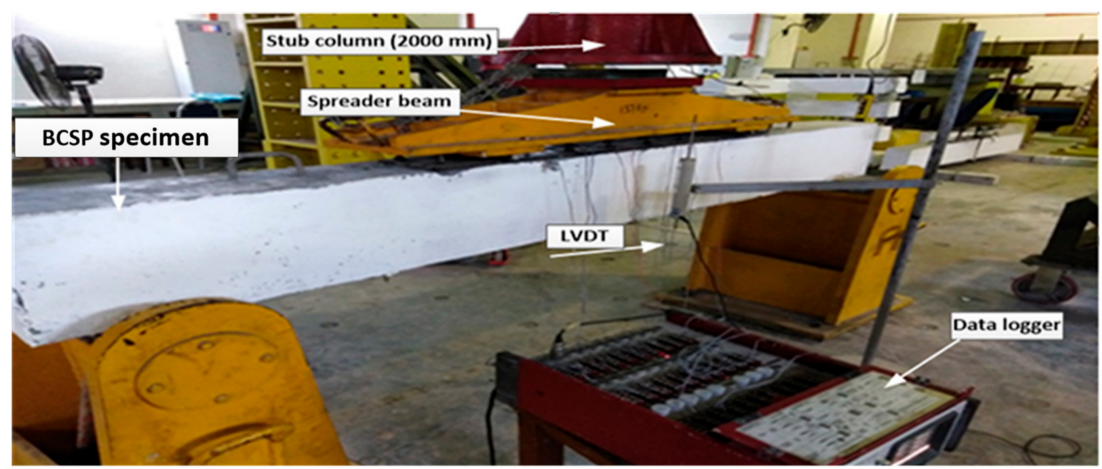

Figure 4. Over-reinforced concrete beam experiment test setup for all of the tested specimens. LVDT: Linear variable displacement transducer.

Table 1. Detailing of the over-reinforced concrete beam specimens.

\begin{tabular}{|c|c|c|c|c|c|c|c|c|c|}
\hline \multirow{2}{*}{$\begin{array}{c}\text { Specimen } \\
\text { Designation }\end{array}$} & \multicolumn{2}{|c|}{ Reinforcement } & \multicolumn{2}{|c|}{ Steel Plate (mm) } & \multirow{2}{*}{$\begin{array}{c}\text { No. of } \\
\text { Bolts }\end{array}$} & \multirow{2}{*}{$\varrho \%$} & \multirow{2}{*}{$\varrho \mathbf{b} \%$} & \multirow{2}{*}{$\begin{array}{c}\text { Shear Span } \\
\text { Ratio (a/d) }\end{array}$} & \multirow{2}{*}{$\begin{array}{l}\text { Stirrup Spacing } \\
(\mathrm{mm}) 6 \varnothing(\mathrm{c} / \mathrm{c})\end{array}$} \\
\hline & Ten. & Com. & $\mathbf{t}$ & L & & & & & \\
\hline CB & $5 \varnothing 20$ & $2 \varnothing 6$ & - & - & - & 3.27 & 2.856 & 2.7 & 50 \\
\hline BCSP-6 & $5 \varnothing 20$ & $2 \varnothing 6$ & 6 & 1100 & 24 & 3.27 & 2.856 & 2.7 & 50 \\
\hline BCSP-10 & $5 \varnothing 20$ & $2 \varnothing 6$ & 10 & 1100 & 24 & 3.27 & 2.856 & 2.7 & 50 \\
\hline BCSP-15 & $5 \varnothing 20$ & $2 \varnothing 6$ & 15 & 1100 & 24 & 3.27 & 2.856 & 2.7 & 50 \\
\hline
\end{tabular}


Table 2. Concrete mix proportions by weight $\left(\mathrm{kg} / \mathrm{m}^{3}\right)$.

\begin{tabular}{ccccc}
\hline Cement (kg) & Fine Aggregate & Coarse Aggregate & Water (kg) & W/C (\%) \\
\hline 375 & 888 & 933 & 150 & 0.4 \\
\hline
\end{tabular}

\subsection{Test Results and Discussion}

\subsubsection{Effect of the Steel Plate's Thickness on the Failure Modes}

All the over-reinforced beams used in this study were designed to fail in compression. Tables 3 and 4 display the test results. As shown in Figure 5, as the applied loads increased, the flexural cracks were initiated and slowly propagated from the mid-span of the beam. New vertical cracks were developed after the formation of flexural cracks around the mid-span, extending to the support of the beam. A further increase in load extended the existing flexural cracks at the web shear into flexural-shear cracks. Also, there was a noticeable increase in the dimensions of the widths and lengths of the cracks at the loading point after the formation of the flexural-shear cracks. Horizontal cracks also widened significantly under the loading points.

The concrete cover began to crack at higher loads, and the initial cracks were identified at the compression zone, causing the concrete cover to spall off in compression at the region of the maximum bending moment. This mode of failure is referred to as the crushing of concrete in the compression zone. This type of failure is illustrated in Figure $5 a$, which shows the brittle failure of the CB.

For the BCSP beams, it was observed that the majority of cracks continued to extend gradually as the applied load increased. Additional cracks were observed on the concrete cover of the BCSP- 6 beam from the two sides of the points of load application. The beams exhibited a form of pseudo ductility, or reserve capacity, in being able to withstand additional loads. The concrete cover began to crack at higher loads, and the initial cracks were identified at the compression zones under the two loading points. The frequency of the formation of additional cracks then decreased. The beam remained ductile, with a slight decrease in load, until total failure occurred without crushing in compression at the middle zone. This prevented the brittle failure of the BCSP-6 beam, an event that was shared with the CB. Here, Figure $5 b$ illustrates the failure mode.

A similar observation was made for the BCSP-10 beam, which had a steel plate with a thickness of $10 \mathrm{~mm}$. As the applied load increased, the failure and spalling of the concrete cover began. The beams were also able to sustain and carry the additional load. The failure mode for the BCSP-10 beam is shown in Figure $5 \mathrm{c}$. The load-carrying capacity of the beam was significantly larger. The BCSP-10 beam offered higher resistance to brittle failure than the $\mathrm{CB}$, and also reduced cracking more than the BCSP- 6 beam, which suggests that increasing the thickness of the steel plate can result in better crack resistance and mitigate brittle failures in beams.

Finally, the BCSP-15 beam, with a 15-mm-thick steel plate, was tested. The arrangement was exactly as the others. This beam showed a great increase in stiffness and strength. It was able to withstand and carry additional loads (a reserve capacity or "pseudo ductility") and did not fail by crushing, but instead failed in a flexural mode, as the steel plate yielded. Figure $5 \mathrm{~d}$ shows the failure mechanism of the BCSP-15 beam.

The steel plate of the BCSP beam also yielded (the design has adopted no buckling). The concrete on the surface was not damaged during the failure load for the BCSP beams, which is unlike the CB. Indeed, for the BCSP-10 and BCSP-15 beams, the cross section remained much more intact and was able to maintain a high load level after the peak load. Thus, the over-reinforced beams with normal strength concrete displayed three types of failure modes. The first was the crushing of the concrete cover with mid-span compression, as seen in the CB. The second was the initial spalling of the concrete cover and crushing underneath the loading points. Also, extension of the shear cracks and an increase of crack width within the span were observed in the BCSP- 6 and BCSP-10 beams. The third mode, the most typical mode, was flexural failure, which was observed in the BCSP- 15 beam. 
Table 3. Peak load capacity and mode failure for all of the over-reinforced concrete beam specimens.

\begin{tabular}{|c|c|c|}
\hline $\begin{array}{c}\text { Specimens } \\
\text { Designation }\end{array}$ & $\mathbf{P}_{\text {Peak }}(\mathbf{k N})$ & Failure Mode \\
\hline CB & 375.5 & Crushing, brittle failure \\
\hline BCSP-6 & 652.3 & $\begin{array}{l}\text { Spalling under two loading points (flexural compression shear) and } \\
\text { yield of the steel plate. }\end{array}$ \\
\hline BCSP-10 & 837.6 & Spalling under two loading points and yield of steel plate. \\
\hline BCSP-15 & 935.3 & Flexural and yield of steel plate (no spalling of the concrete). \\
\hline
\end{tabular}

Table 4. Measured values of the load types of all of the over-reinforced concrete beam specimens.

\begin{tabular}{cccccccccccc}
\hline $\begin{array}{c}\text { Specimens } \\
\text { Designation }\end{array}$ & $\begin{array}{c}\mathbf{P}_{\mathbf{c r}} \\
\mathbf{( k N )}\end{array}$ & $\begin{array}{c}\mathbf{P}_{\text {cr }} \% \\
\mathbf{I n c r e a s e}\end{array}$ & $\begin{array}{c}\boldsymbol{\Delta} \\
(\mathbf{m m})\end{array}$ & $\begin{array}{c}\mathbf{P}_{\text {Spall }} \\
\mathbf{( k N )}\end{array}$ & $\begin{array}{c}\mathbf{P}_{\text {Spall }} \mathbf{\%} \\
\mathbf{I n c r e a s e}\end{array}$ & $\begin{array}{c}\mathbf{P}_{\text {Yieldl }} \\
\mathbf{( k N )}\end{array}$ & $\begin{array}{c}\boldsymbol{\Delta}_{\text {spall }} \\
(\mathbf{m m})\end{array}$ & $\begin{array}{c}\Delta_{\text {Yield }} \\
(\mathbf{m m})\end{array}$ & $\begin{array}{c}\mathbf{P}_{\text {Peak }} \\
\mathbf{( k N )}\end{array}$ & $\begin{array}{c}\mathbf{P}_{\text {Peak }} \\
\mathbf{I n c r e a s e}\end{array}$ & $\begin{array}{c}\boldsymbol{\Delta}_{\text {peak }} \\
(\mathbf{m m})\end{array}$ \\
\hline CB & 71.5 & - & 1.87 & 356 & - & - & 8.33 & - & 375.5 & - & 10.8 \\
\hline BCSP-6 & 247 & 245.5 & 3.48 & 521 & 46.3 & - & 8.2 & - & 652.3 & 73.7 & 11.7 \\
\hline BCSP-10 & 362 & 406.3 & 3.73 & 635 & 78.4 & - & 6.9 & - & 837.6 & 123 & 12.5 \\
\hline BCSP-15 & 460 & 543.5 & 3.99 & - & - & 935.3 & - & 10.2 & 935.3 & 149 & 15.5 \\
\hline
\end{tabular}

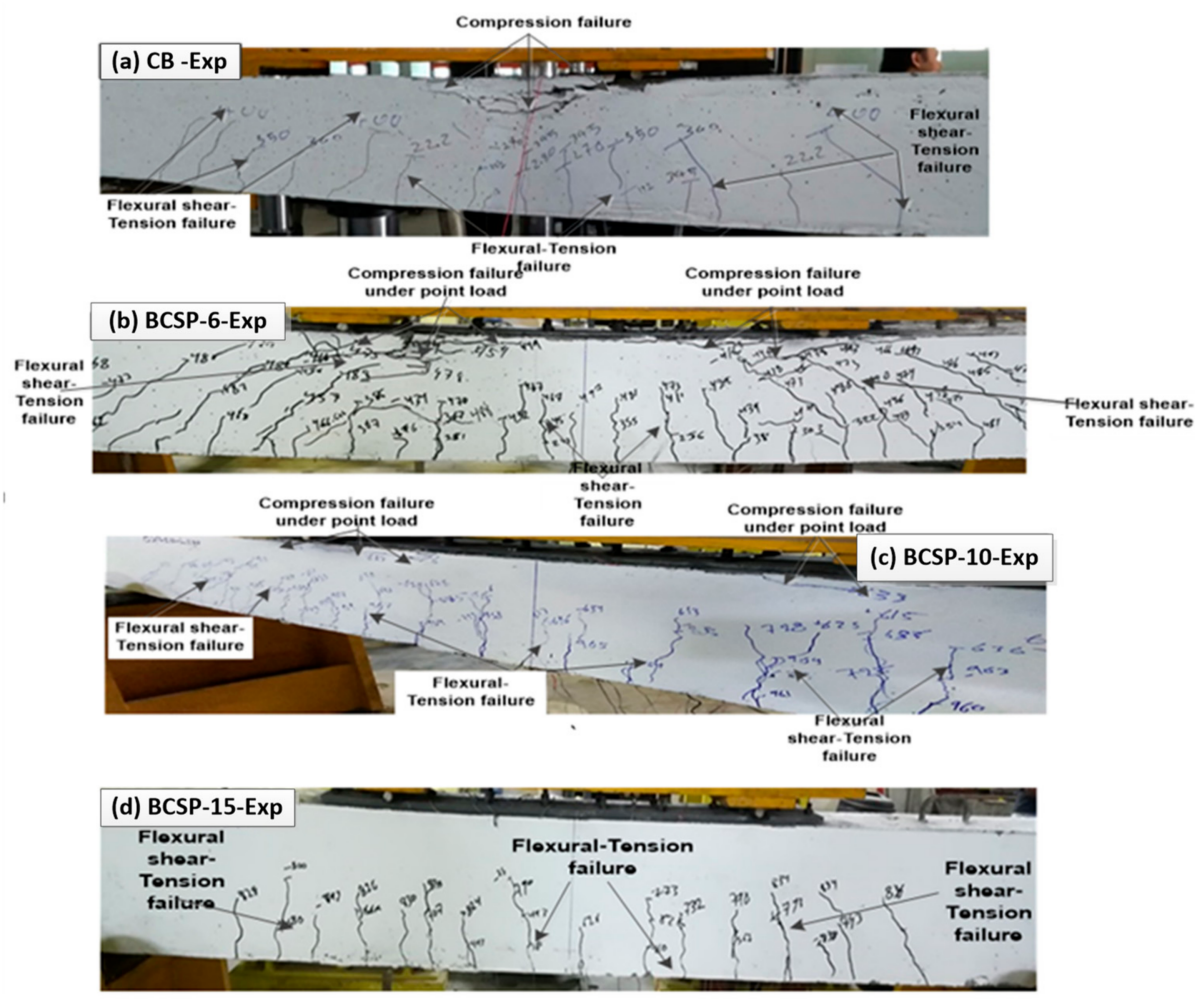

Figure 5. Modes of failure and crack patterns of all of the specimens: (a) CB; (b) BCSP-6; (c) BCSP-10 and (d) BCSP-15.

\subsubsection{Effect of Steel Plate Thickness on Concrete and Steel Strains}

Figure 6 shows the strain development during the loading of the beams. The positioning of the strains is such that the concrete strains are on the top surfaces of the beams in the longitudinal direction, whereas the steel plate and longitudinal reinforcement strains are in the bottom rebar. After spalling, a very brittle response was exhibited by the $C B$ at a normal strain, as shown in Figure 6a, however, the BCSP beams with bolted steel plates experienced a remarkable increase in bending capacity in the compression zone, even at large strains. Here, the steel plates contributed to the ductile behavior of the 
concrete. The large compressive strains led to an increase in material stiffness, and the lateral expansion of the beam was reduced. This resulted in an increase in the compressive ductility. The front elevation of each beam is presented in Figure 6, which illustrates the strain distributions in the cross section at both spalling and peak loads. Beyond $\mathrm{P}_{\text {spall }}$ loading, the concentration of the strain is introduced towards the middle of the span of the beam, due to the emergence of a plastic hinge region. This phenomenon can be observed in the BCSP- 6 beam, since the strains in its compressive reinforcement increased more than the average strain on the top surface, from $\mathrm{P}_{\text {spall }}$ to $\mathrm{P}_{\text {peak }}$. The load-strain behavior for the concrete $\left(\varepsilon_{c} \cdot a v g\right)$ beams is also shown in Figure 6a. The average concrete strain was found to be 0.0026 , based on a linear regression analysis of the loading data until spalling (i.e., the crushing of the concrete cover). A full failure of the cross section was observed for the CB shortly after the spalling load was applied. This failure was very brittle in nature. Linear regression was not fit to determine the average concrete strain for the steel plate for the BCSP-6, BCSP-10, and BCSP-15 beams. The concrete strains at failure for these beams were found to be $0.003,0.0035$ and 0.0038 , respectively. These values are consistent with the assumed maximum compressive strain values of 0.003 and 0.0035 , according to the ACI and CSA $[28,36]$, respectively. For these beams, the tension reinforcement strains from the tests at a spalling load exhibited elastic behavior without failure until the peak load was reached. After the crushing of the beam, the tension reinforcement yielded, as shown in Figure 6. At higher strains of the BCSP beams on the steel bars, the beams withstood more loading. This means that the beams can carry higher loads without failure at the same strain as the steel bar. At much higher applied loads, yielding of the steel plates occurred, which was localized under the flexural loading area. The steel plate exhibited plastic strain until the point of peak loading, and yielding of the steel plates was initiated before the crushing of the concrete progressed, as shown in Figure 6.

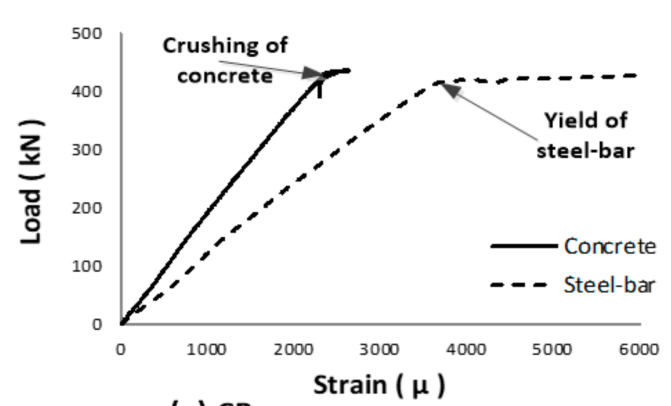

(a) $\mathrm{CB}$

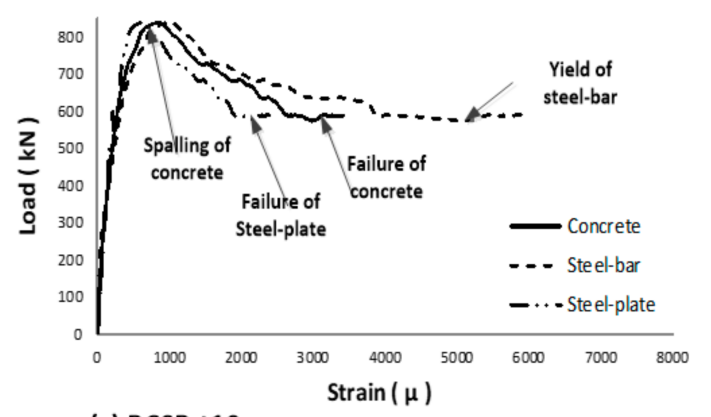

(c) BCSP-t10

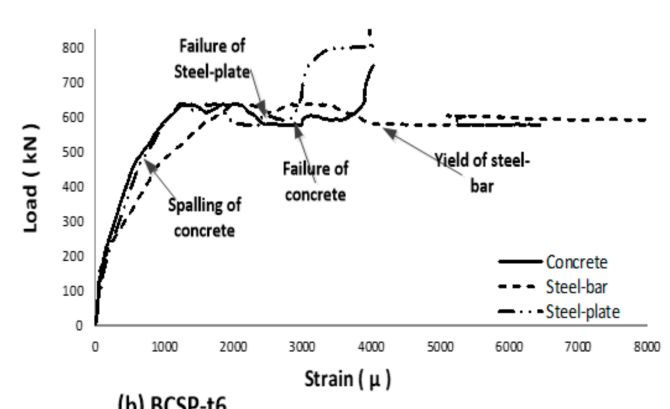

(b) BCSP-t6

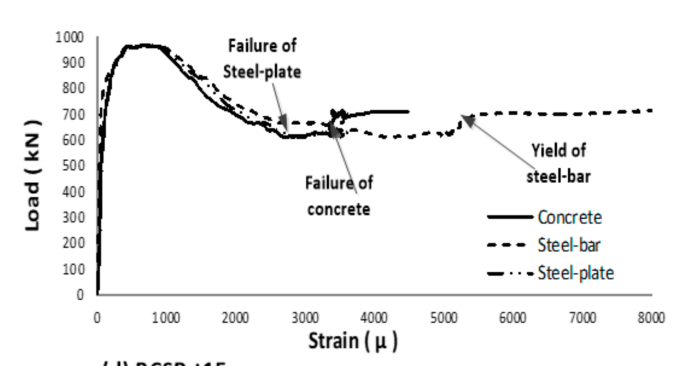

(d) BCSP-t15

Figure 6. Load-strain relationships for all the beam specimens' applied strains until failure.

\subsubsection{Effect of the Steel Plate's Thickness on Flexural Strength and Energy Absorption}

The load and mid-span displacement responses of the over-reinforced beams vary significantly depending on their steel plate thickness. The characteristic bending response of the beams was considered in an attempt to describe the response of the tested specimens. The loading reading was carried out in five stages, as illustrated in Figure 7. The peak load that produced the center point of deflection, $\Delta_{\text {spall }}$, was identified as the load at which horizontal cracking occurred in the compression 
zone, denoted as $\mathrm{P}_{\text {spall }}$. The peak load, $\mathrm{P}_{\text {peak }}$, with deflection, $\Delta_{\text {peak }}$, is the next highest load obtained after the spalling load. This second peak occurred due to the deformation-controlled testing system and the confinement effect.

Figure 7 shows five stages of the response curve for each specimen. The first stage is the stage before the concrete cracks, represented by points $\mathrm{O}$ to $\mathrm{A}$ in the curve. The second stage represents a linear response for an already cracked cross section from $A$ to $B$ in the curves. The third stage shows the non-linear response, which is the stage before the beams reach their compressive capacity. This stage is the strain limit of the beams when the spalling of the compression zone is initiated, as indicated by segments $B$ to $C$ on the curves. The fourth stage, $C$ to $D$, was observed for the BCSP beams but not for the $C B$. The $C B$ exhibited a more brittle failure that made it fail after stage four (shown as $\mathrm{C}$ to $\mathrm{F}$ ). The BCSP beams were more ductile and they withstood a longer post-peak strain (shown from D to F). This last stage developed due to the existing steel plates. Which increased stiffness and strength. The ultimate loads and maximum strains increased with an increase of the steel plate thickness, which suggests that the greater the steel plate thickness, the more improvement is achieved. The BCSP-15 beam was the stiffest and strongest.

The CB failed immediately after reaching its maximum capacity. This shows its brittle nature (spalling at load). The responses for the beams show that the behaviors of the beams are greatly influenced by their different confinement configurations. The confinement configurations had no significant influence at the stages before the spalling load. However, the elastic bending stiffness increased when the confinements were introduced into the compression zone. At first cracking, the increase in the load capacity of the BCSP beams was $245.5 \%, 406.3 \%$ and $543.5 \%$ for BCSP- 6 , BCSP-10 and BCSP-15, respectively, in comparison with the CB. The increase in the spall loads was $46.3 \%$ and $78.4 \%$ for BCSP- 6 and BCSP- 10 , respectively, whereas increases in the peak loads were $73.7 \%$, $123 \%$ and $149 \%$ for BCSP-6, BCSP-10 and BCSP-15, respectively, in comparison with the CB, as shown in Table 4.

The energy absorption (EA) capacities of the beams were estimated by calculating the areas under the load-displacement curves, as demonstrated in Figure 7 [37-39]. The BCSP beams showed higher EA capacity values than the $C B$ beam. They achieved higher load capacities and stiffness values than the control specimens. The CB beam had the lowest energy absorption capacity, at $4030 \mathrm{kN} \cdot \mathrm{mm}$. The BCSP beam specimens' flexural capacity also, energy absorption increased with the steel plate thickness. The rates of increase were $247.5 \%, 317.5 \%$, and $458.3 \%$ for the BCSP-6, BCSP-10, and BCSP- 15 beams, respectively. The highest value of energy absorption recorded for the specimen had a BCSP with a steel plate thickness of $15 \mathrm{~mm}$. Its energy absorption capacity was about 22,500 $\mathrm{kN} \cdot \mathrm{mm}$.

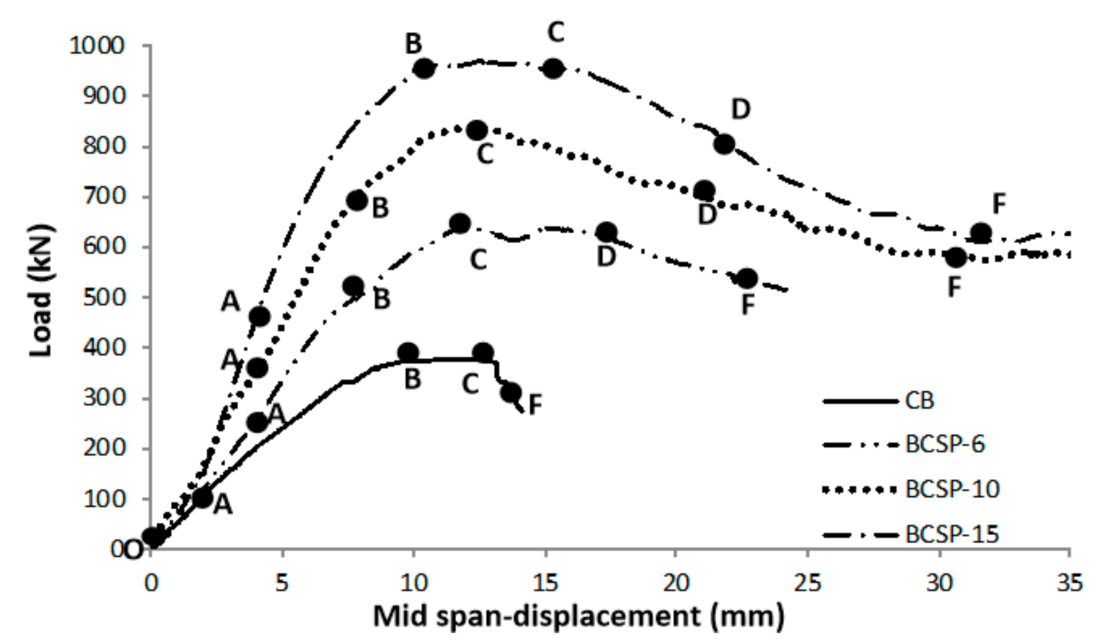

Figure 7. Load-displacement plots for all of the over-reinforced concrete beam specimens. 


\section{Numerical Study}

The ABAQUS software package [30] was used for finite element modeling and the analysis of the over-reinforced concrete beams with the BCSP system. Five full-scale specimens were analyzed ( 1 as the CB and 4 with steel plates as the BCSP beams). All beams were subjected to flexural loading. The objective of the FE analysis was to validate, by modeling, the experimental work in the study. All of FE models were comprised of two materials, namely, concrete and steel.

\subsection{Material Properties of the Finite Element (FE) Models}

\subsubsection{Steel Reinforcement}

Three types of steel were used in this study, namely, steel bars, steel plates, and bolts with nuts. The diameters of the main reinforcement bars under tension were $20 \mathrm{~mm}$. Plain bars with a diameter of $6 \mathrm{~mm}$ were placed at the top sections of the beams in order to fix the $6 \mathrm{~mm}$ stirrups. The steel plates were $1100 \mathrm{~mm}$ in length, with a varying $6 \mathrm{~mm}, 10 \mathrm{~mm}$, and $15 \mathrm{~mm}$ thickness, depending on the given specimen). Here, 24 bolts with nuts were used, which were $12 \mathrm{~mm}$ in diameter and $200 \mathrm{~mm}$ in length.

The values of the mass density, Young's modulus, Poisson's ratio, and isotropic behavior of the steel reinforcement, bolts, nuts, and steel plates were determined. The properties of the steel are shown in Tables 5-7. These values were taken from the manufacturing and coupon tests considered during the experimental tests adopted in previousstudies [40-42]. The elastic-isotropic option was used to model the steel materials. The yield strength and the plastic strain values were modeled using the plastic-isotropic option.

Table 5. Material properties of the rebars used in the FEM.

\begin{tabular}{cccccc}
\hline Steel Bars & $\begin{array}{c}\text { Mass Density } \\
\left(\mathbf{k g} / \mathbf{m m}^{\mathbf{3}} \mathbf{)}\right.\end{array}$ & $\begin{array}{c}\text { Young's Modulus } \\
\mathbf{( M P a )}\end{array}$ & Poisson Ratio & $\begin{array}{c}\text { Yield Stress } \\
\mathbf{( M P a )}\end{array}$ & Plastic Strain \\
\hline Steel G6 & $7.85 \times 10^{6}$ & 200,000 & 0.3 & 275 & 0.2 \\
\hline Steel G20 & $7.85 \times 10^{6}$ & 200,000 & 0.3 & 460 & 0.2 \\
\hline
\end{tabular}

Table 6. Material properties of the bolts and nuts used in the FEM.

\begin{tabular}{cccccc}
\hline $\begin{array}{c}\text { Material } \\
\text { Grade 10.9 }\end{array}$ & $\begin{array}{c}\text { Mass Density } \\
\left(\mathbf{k g} / \mathbf{m m}^{\mathbf{3}}\right)\end{array}$ & $\begin{array}{c}\text { Young's Modulus } \\
\mathbf{( M P a )}\end{array}$ & Poisson Ratio & $\begin{array}{c}\text { Yield Stress } \\
\mathbf{( M P a )}\end{array}$ & Plastic Strain \\
\hline M12 & $7.85 \times 10^{6}$ & 200,000 & 0.3 & 740 & 0.2 \\
\hline
\end{tabular}

Table 7. Material properties of steel plates used in the FEM.

\begin{tabular}{cccccc}
\hline Steel Plate & $\begin{array}{c}\text { Mass Density } \\
\left(\mathbf{k g} / \mathbf{m m}^{\mathbf{3}} \mathbf{)}\right.\end{array}$ & $\begin{array}{c}\text { Young's Modulus } \\
\mathbf{( M P a )}\end{array}$ & Poisson Ratio & $\begin{array}{c}\text { Yield Stress } \\
\mathbf{( M P a )}\end{array}$ & Plastic Strain \\
\hline $\mathbf{6}$ & $7.85 \times 10^{6}$ & 208,000 & 0.3 & 243 & 0.2 \\
\hline $\mathbf{1 0}$ & $7.85 \times 10^{6}$ & 201,000 & 0.3 & 255 & 0.2 \\
\hline $\mathbf{1 5}$ & $7.85 \times 10^{6}$ & 203,000 & 0.3 & 237 & 0.2 \\
\hline
\end{tabular}

\subsubsection{Concrete}

In this study, the mechanical properties of concrete and its damaged plasticity parameters were considered when modelling the concrete. For modelling the concrete's behavior under tension and compression, the damaged plasticity model is very effective [40,42]. A concrete damage grade of C40 was defined, along with the plasticity and failure criteria for the beams during the application of the load.

The CDP model was used in the finite element software ABAQUS [30]. This model is capable of carrying out static and dynamic analyses of RC members with embedded bars. This model considers 
the tensile and compressive failure modes of isotropic materials. This model can also analyse the reduction in stiffness and the permanent damage that occurs during the fracture process. Figure $8 \mathrm{a}, \mathrm{b}$ show the response of the concrete to uniaxial tension and compression, respectively.

A compressive model was adopted. This model depends on two parameters. The first is the modulus of elasticity and the second is the compressive strength of the concrete. The compressive model explains the stress-strain behavior of concrete in relation to existing models [43,44]. Equation (1) shows the relationship between the concrete's compressive strength and the modulus of elasticity in MPa [42].

$$
E c=3320 \sqrt{f}^{\prime} c+6900
$$

The values of the dilation angle, eccentricity, $\mathrm{f}_{\mathrm{b} 0} / \mathrm{f}_{\mathrm{c} 0}, \mathrm{~K}$, and the viscosity parameter were chosen as the default for the CDP models, which were $35,0.1,1.16,0.667$, and 0.01 , respectively [43-45] Table 8 offers a summary of the mechanical properties of the concrete. Other parameters that relate to the compressive and tensile strengths are shown in Figure 9.
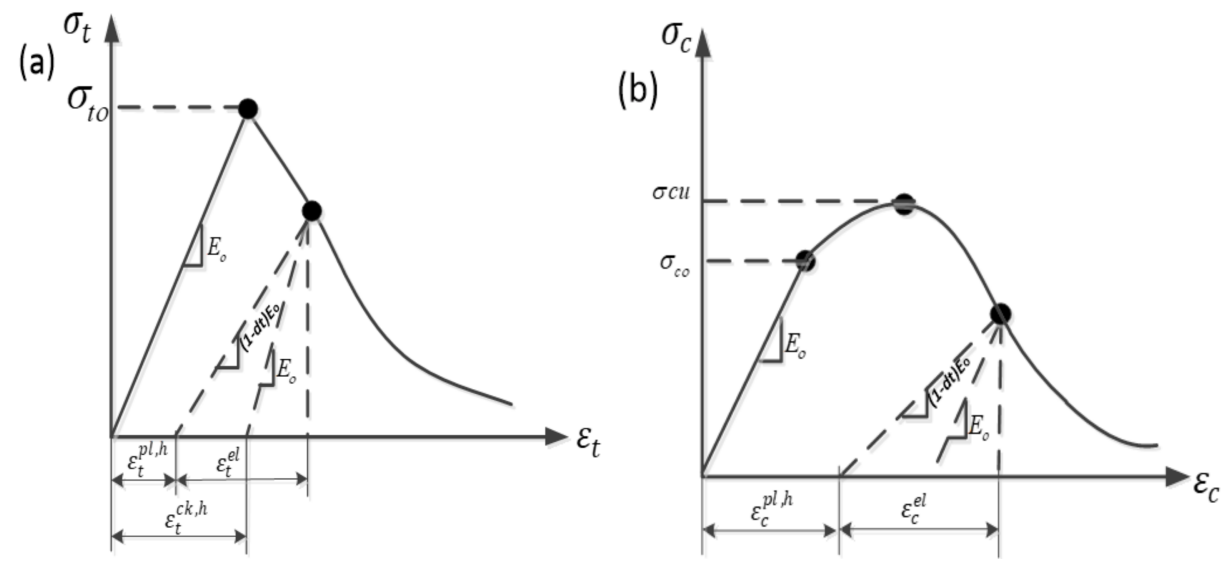

Figure 8. The response of the concrete to uniaxial loading under (a) tension and (b) compression.
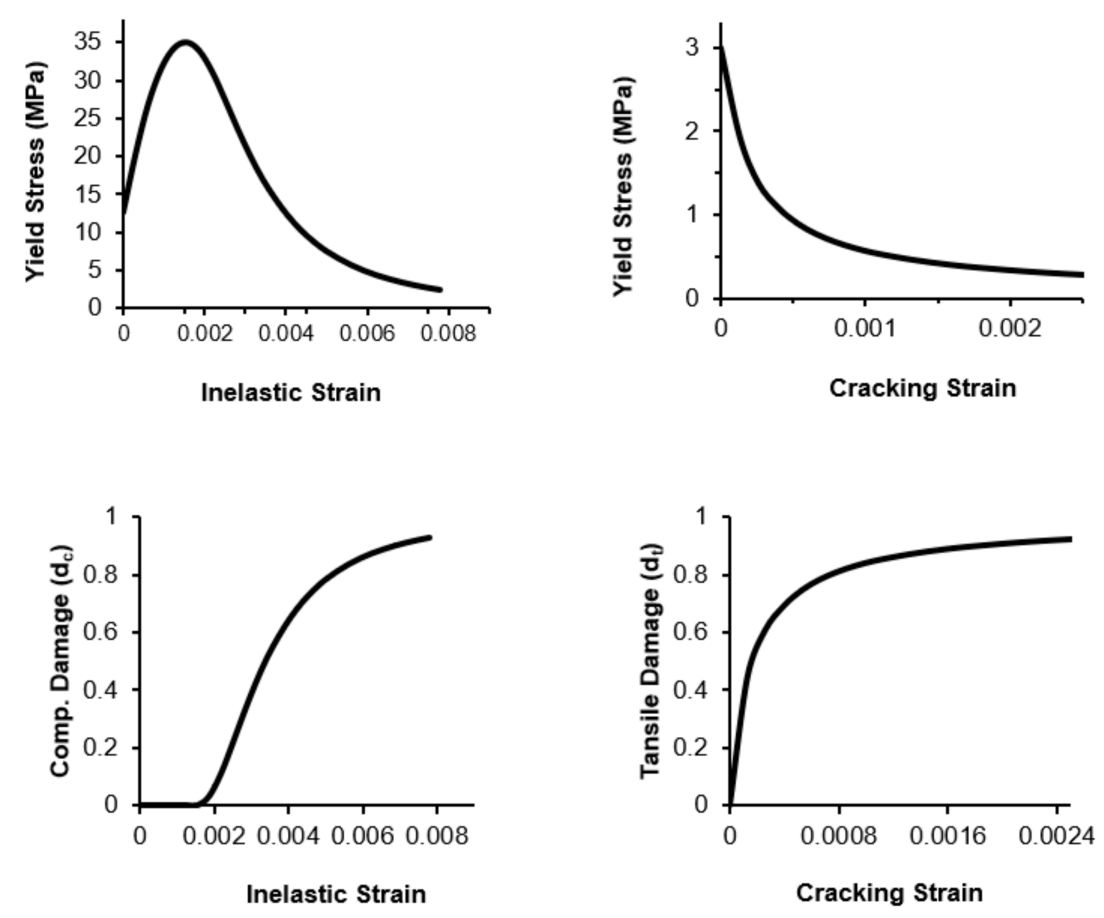

Figure 9. Uniaxial stress-strain and damage-strain relationships. 
Table 8. Material properties of the concrete used in the FEM.

\begin{tabular}{cccccc}
\hline $\begin{array}{c}\text { Material } \\
\text { Concrete }\end{array}$ & $\begin{array}{c}\text { Mass Density } \\
\left(\mathbf{k g} / \mathbf{m m}^{3}\right)\end{array}$ & $\begin{array}{c}\text { Young's Modulus } \\
\mathbf{( M P a )}\end{array}$ & Poisson Ratio & fcu (MPa) & fct (MPa) \\
\hline G40 & $2.4 \times 10^{6}$ & $26,541.48$ & 0.2 & 36.08 & 3.68 \\
\hline
\end{tabular}

\subsection{Mesh Discretization and Boundary Conditions}

To model the concrete elements, a 3-dimensional, 8-noded hexahedral element with 3 degrees of freedom in each node (C3D8R) was used. The reinforcements were modelled using a truss element (T3D2) with 3 degrees of freedom in each node. The model geometry was divided into several parts, with simple shapes and less complex geometry to create uniform meshes. Different mesh algorithms were used to try to improve the meshing. The medial axis algorithm was used to produce the swept mesh, as shown in Figure 10. This figure shows the assembly of all of the concrete beam models meshed with a $25 \mathrm{~mm}$ element and a $12.5 \mathrm{~mm}$ steel plate, bolt, and nut assembly.

Figure 10 shows the rebar and bolts that were embedded in the concrete in the interactive model while assigning the concrete as the host. Thus, the rotations and translations of the reinforcing bar and bolt elements were equal to those of the host elements surrounding them (i.e., a perfect bond) [46-49]. The bond between the steel plate and concrete surface was modelled using the two materials' cohesive behavior. The node coupled method was used to model the bolts, whereas the nodes of the steel reinforcing bar and the steel plate were coupled (Figure 2 details this reinforcement). Figure 1 shows the boundary conditions of the simply-supported beam. All beams were subjected to flexural loading after the modelling was completed, and the results of the entire analysis were investigated.

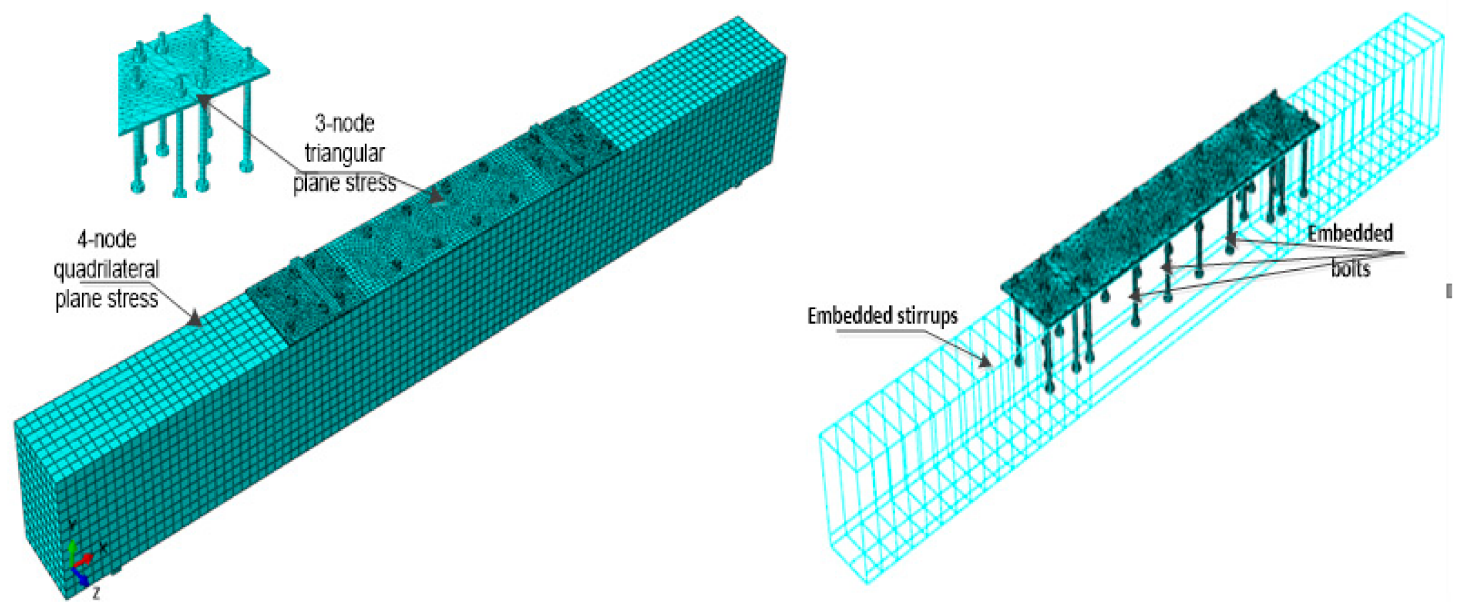

Figure 10. Mesh discretization for all the over-reinforced specimens.

\subsection{Convergence Between Mesh Size and Cracking}

Figure 11 shows a comparison between some FE models with different mesh sizes. The maximum load-carrying capacity of the FE model was compared to the maximum failure load observed in the experimental test. To verify the selected meshing size for the suggested FE models, a convergence study was conducted on the CB and BCSP beams using the FE model. The FE model, with a mesh size of 25, was adopted for this study. This model satisfied the failure load with a reasonable $\mathrm{P}_{\text {Peak,Exp }} / \mathrm{P}_{\text {Peak,FE }}$ percentage value. Furthermore, its curve behavior was better than that of the experimental model. The crack patterns were observed with high clarity and accuracy, where the inclined crack formation in the beam under each damage level can be observed, as shown in Table 9 . 


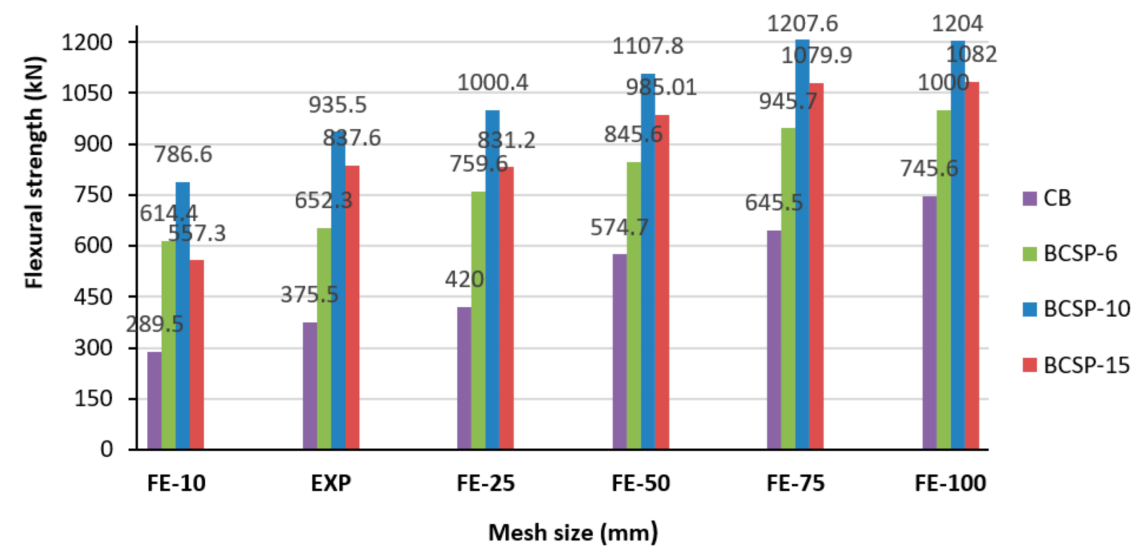

Figure 11. Comparison between the mesh sizes for all FE models.

Table 9. Comparative (compressive damage of the BCSP-10 beam) mesh size convergence study.

\begin{tabular}{cccc}
\hline Mesh Size (mm) & $\mathbf{P}_{\text {peak }}(\mathbf{k N})$ & Max Stress (S), Mises (MPa) & FE Model (Compressive Damage) \\
\hline 10 & 614 & 741.4 & \\
\hline 25 & 813.2 & 748.6 & \\
\hline 50 & 985.01 & 747.0 & \\
\hline 75 & 1079.9 & 742.5 & 714.6 \\
\hline
\end{tabular}

\subsection{Results and Discussion of Finite Element Modelling}

\subsubsection{Verification of the Numerical Model by Using Experimental Results}

The experimental and numerical load-deflection curves for all the beam specimens are shown in Figure 12. As a result of other imperfections, such as gaps between the components of experimental specimens that cannot be fully simulated by the numerical models, an ascending segment of the load-displacement curves was observed in the numerical results. The comparison results show that the FE load-deflection curves are generally expected to be stiffer than in the experimental plots.

The stiffness of the FE models was even higher than that of the experimental beams after first cracking. Several factors may have contributed to this. The micro-cracks that exist in the concrete are the most important factor in this experimental design. These micro-cracks could be produced by drying shrinkage in the concrete and/or as a result of the handling of the beams, since the FE models do not include micro-cracks, which could reduce the stiffness of all experimental beams. Moreover, the FE load-displacement curves almost follow the same design trend as the experimental results. The load-deflection relationship of the FE models is in good agreement with the experimental results, prior to the failure load for all specimens.

The mean load ratios of the experimental to FE peak loads were $0.87 \%, 0.86 \%, 1.01 \%$ and $0.98 \%$. Also, the average deflection ratios of the experimental to FE deflection at peak load were $1.09 \%, 0.79 \%$, $0.69 \%$ and $1.2 \%$ for the CB, BCSP-6, BCSP- 10 , and BCSP- 15 beam specimens, respectively, as shown in Table 10.

The design recommendations of the ACI-code and CSA [28,36], which depend on stress-strain diagrams, were used to calculate the nominal load capacities $\left(P_{n}\right)$. The ratios of the normal load $\left(\mathrm{P}_{\mathrm{n}}\right)$ to the spalling load of the experimental ( $\left.\mathrm{P}_{\mathrm{Spall}} \mathrm{EXP}\right)$ beam specimens were $0.99 \%, 0.98 \%$, and $1 \%$. Those equal to the ratio of the normal load to the spalling load of the $\mathrm{FE}\left(\mathrm{P}_{\mathrm{n}} / \mathrm{P}_{\text {Spall,FE }}\right)$ were $0.89 \%$, $1.03 \%$, and $1.06 \%$. Those equal to the ratio of the spalling load of the experimental to the spalling load 
of the FE $\left(\mathrm{P}_{\text {spall,EXP }} / \mathrm{P}_{\text {spall,FE }}\right)$ were $1.11 \%, 0.95 \%$, and $0.94 \%$ for the CB, BCSP-6, and BCSP-10 beam specimens, respectively, while the BCSP-15 beam specimen experienced flexural failure, as shown in Table 11. The finite element analysis gave accurate values of $P_{\text {spall }}$ for all of the beams. Both the experimental and predicted results were in very good agreement. Also, the load-deflection curve from the experiment was in agreement with the FE analysis. The results indicate that the constitutive models of this study can be used to accurately predict the behavior of over-reinforced concrete with steel plates without buckling failure.

Increasing the area of the steel plate induced a sharp increase in the ductility of the BCSP beams. Small displacements caused the failure of the beams when compared with the CB. The stress response of the over-RC beams for four different analyses is demonstrated in Figure 13. From this figure, it can be concluded that, with reference to the stress response, the difference of the stress for the four models can be presented. The steel plate of the BCSP beam yielded first. In the finite element analysis, yielding of the tie and steel bars in tension was observed without failure. Extensive cracking was observed for the compression-shear failure and flexural failure of the BCSP- 6 and BCSP- 10 beams. The yielding region expanded to the beam when the loading increased. The stress concentration increased at the two loading points during later loads, after which plastic strains developed in the entire section of the beam.

The von Mises stresses, which represent the inelastic behavior of the beam sections, are shown in Figure 13. It was observed that the maximum stress was concentrated at the bolts. For all the BCSP beams, the maximum von Mises stress was $756.6 \mathrm{MPa}$, located at the bolts under the two points of loading. This maximum principal stress of the BCSP beams could have led to the ductile failure of the BCSP beams via the spalling of concrete under the loading points. The minimum principal stress contour plots of the concrete under the finite element model's stress states during peak load. A comparison was made between the FEA predicted and experimentally measured applied load-strain curves. Figure 6 includes comparisons of the experimentally measured applied load, including the average concrete strain, the longitudinal strain at tension, and the strain at the top of the steel plate. As shown, the analytical prediction compares very well with the experimental results. These comparisons are excellent at the global level (Figure 13), where the yielding of the bolts at the two load points, the steel plate, and the steel bars occur, respectively.

The energy absorption (EA) of the BCSP-6, BCSP-10, and BCSP-15 beams increased by about $300 \%, 327 \%$, and $462 \%$ as compared to the CB, respectively. This result indicates that the BCSP beams developed increased stiffness and energy absorption with the increased thicknesses of their steel plates. The values for the test results and FE modelling of the EA for all the models are shown in Table 12 and Figure 14.

Table 10. Comparison between the results derived from the experiment and FEM.

\begin{tabular}{ccccccc}
\hline $\begin{array}{c}\text { Specimens } \\
\text { Designation }\end{array}$ & $\begin{array}{c}\mathbf{P}_{\text {peak,Exp }} \\
\mathbf{( k N )}\end{array}$ & $\begin{array}{c}\mathbf{P}_{\text {Peak,FE }} \\
\mathbf{( k N )}\end{array}$ & $\begin{array}{c}\mathbf{P}_{\text {Peak, Exp }} / \mathbf{P}_{\text {Peak, FE }} \\
\mathbf{( \% )}\end{array}$ & $\boldsymbol{\Delta}_{\text {Exp }}(\mathbf{m m})$ & $\begin{array}{c}\boldsymbol{\Delta}_{\mathrm{FE}} \\
(\mathbf{m m})\end{array}$ & $\begin{array}{c}\boldsymbol{\Delta}_{\text {Exp/ }} \boldsymbol{\Delta}_{\mathrm{FE}} \\
(\mathbf{m m})\end{array}$ \\
\hline $\mathbf{C B}$ & 375.5 & 420 & 0.89 & 10.98 & 11.5 & 1.09 \\
\hline BCSP-6 & 652.3 & 759.6 & 0.86 & 11.7 & 17.34 & 0.79 \\
\hline BCSP-10 & 837.6 & 831.2 & 1.01 & 12.5 & 18.2 & 0.69 \\
\hline BCSP-15 & 935.3 & 1000.4 & 0.93 & 15.5 & 13.07 & 1.2 \\
\hline
\end{tabular}


Table 11. Experimental, FEM, and nominal predictions of the spalling loads of the tested samples.

\begin{tabular}{cccccccc}
\hline $\begin{array}{c}\text { Specimens } \\
\text { Designation }\end{array}$ & $\begin{array}{c}\mathbf{P}_{\text {Spall,Exp }} \\
\mathbf{( k N )}\end{array}$ & $\begin{array}{c}\mathbf{P}_{\text {Yield,Exp }} \\
\mathbf{( k N )}\end{array}$ & $\mathbf{P}_{\mathbf{n}} \mathbf{( k N )}$ & $\begin{array}{c}\mathbf{P}_{\text {spall,FE }} \\
\mathbf{( k N )}\end{array}$ & $\begin{array}{c}\mathbf{P}_{\mathbf{n}} / \mathbf{P}_{\text {Spall,EXP }} \\
\mathbf{( \% )}\end{array}$ & $\begin{array}{c}\mathbf{P}_{\mathbf{n}} / \mathbf{P}_{\text {Spall,FE }} \\
(\mathbf{\%})\end{array}$ & $\begin{array}{c}\mathbf{P}_{\text {spall,EXP }} / \mathbf{P}_{\text {spall,FE }} \\
\mathbf{( \% )}\end{array}$ \\
\hline CB & 356 & - & 354 & 400 & 0.99 & 0.89 & 1.11 \\
\hline BCSP-6 & 521 & - & 514 & 498 & 0.98 & 1.03 & 0.95 \\
\hline BCSP-10 & 635 & - & 637 & 600 & 1.00 & 1.06 & 0.94 \\
\hline BCSP-15 & - & 935.5 & 850 & - & - & - & - \\
\hline
\end{tabular}

Table 12. Energy absorption: The comparison between the experiment and FEM for all of the over-reinforced concrete specimens. EA: Energy absorption.

\begin{tabular}{|c|c|c|c|c|c|c|}
\hline $\begin{array}{l}\text { Specimens } \\
\text { Designation }\end{array}$ & $\begin{array}{c}\text { EA }_{\text {EXP }} \\
(\mathrm{kN} \cdot \mathrm{m})\end{array}$ & $\begin{array}{c}\mathrm{EA}_{\mathrm{FE}} \\
(\mathbf{k N} \cdot \mathbf{m})\end{array}$ & $\underset{(\%)}{\mathrm{EA}_{\mathrm{Exp}} / \mathrm{EA}_{\mathrm{FE}}}$ & $\begin{array}{c}\text { EA }_{\text {EXP }}(\%) \\
\text { Increase }\end{array}$ & $\begin{array}{l}\mathrm{EA}_{\mathrm{FE}}(\%) \\
\text { Increase }\end{array}$ & $\begin{array}{l}\mathrm{EA}_{\mathrm{Exp}} / \mathrm{EA} \\
(\%) \text { Increase }\end{array}$ \\
\hline CB & 4.03 & 4.3 & 0.94 & - & - & - \\
\hline BCSP-6 & 13.9 & 17.2 & 0.8 & 247.5 & 300 & 0.83 \\
\hline BCSP-10 & 16.7 & 18.4 & 0.91 & 317.5 & 327 & 0.97 \\
\hline BCSP-15 & 22.5 & 24.2 & 0.93 & 458.3 & 462 & 0.99 \\
\hline
\end{tabular}

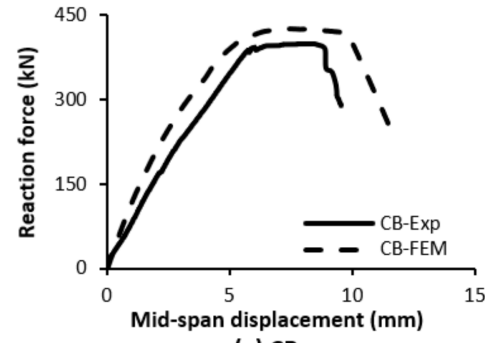

(a) CB

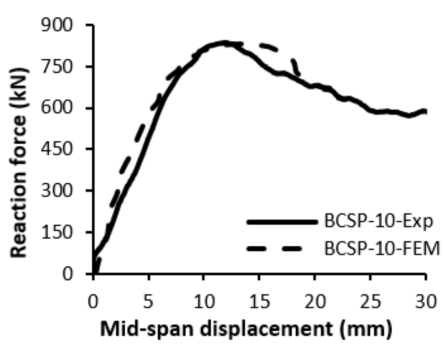

(c) BCSP-10

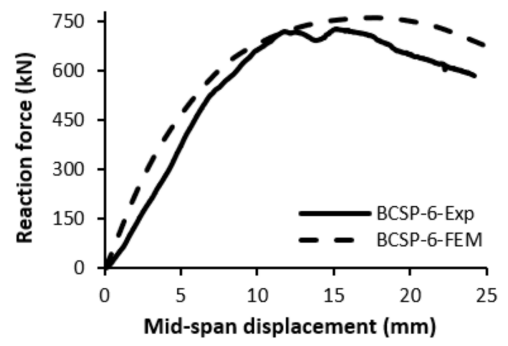

(b) BCSP-6

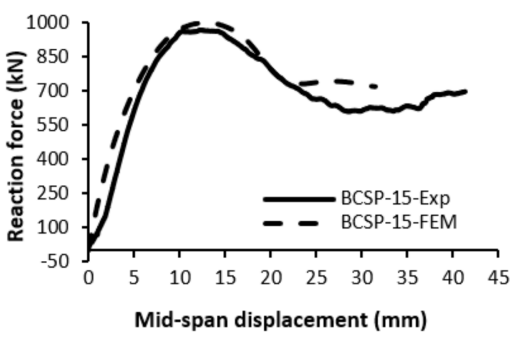

(d) BCSP-15

Figure 12. Comparison of the load-displacement curves derived from the experimental and numerical studies.
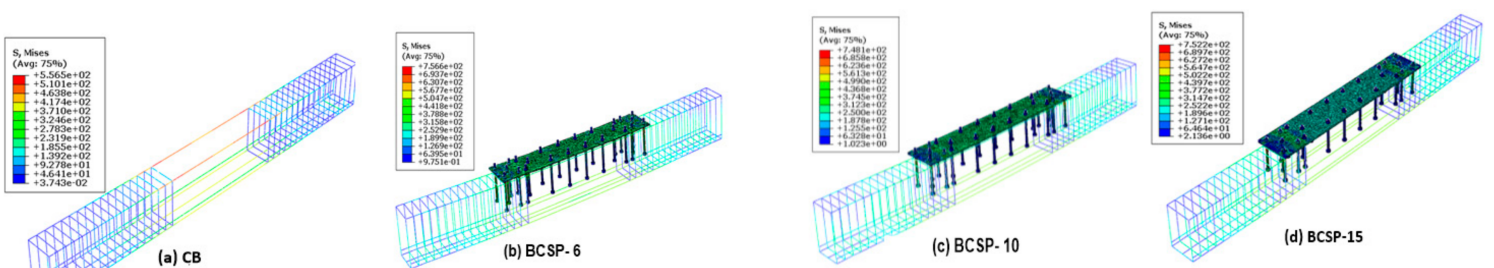

Figure 13. The von Mises stresses for all the beam specimens. 


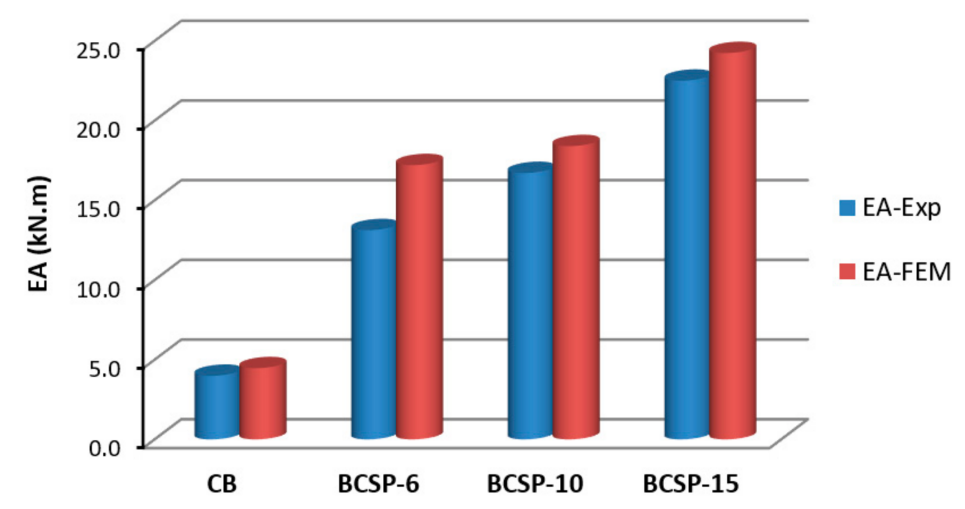

Figure 14. Comparison of the energy absorption between the experiment and FEM.

\subsubsection{Crack Propagations and Failure Mechanisms}

The crack progression was investigated in order to validate the capacity of the model with experimental results. The ABAQUS software package [30] was able to satisfactorily indicate the inclined crack propagations. The major cracks appeared to be vertical. This agrees with the results obtained by Hanif et al. [42]. Figures 15-18 show the formation of cracks due to the flexural and compression damage in the model at maximum load. The vertical cracks are due to tension and the horizontal cracks are due to compression. The capability of the developed model for mixed-mode cracking was further confirmed by the fact that the onset of the vertical cracks inclined at the shear span. This can be separately studied by applying two-point loading. Therefore, the mixed-mode cracking was a combination of flexural, compression, and shear-flexural cracking. This represents a typical real-life case for the nature of the damage induced in the beam structures.

The tensile damage contours shown in Figures 15-18 were obtained from the FE models and the experimental results at different levels for the CB and the BCSP beams. All beams failed under flexural loading. The tensile damage was initiated at the extreme tension fibres of the beam in the zones subjected to pure bending. The cracks were propagated towards the compression zone as the load levels increased. The failure mechanisms observed in the experiments are reported in Table 3. The bending failure mechanisms match the mode failures of the FE analysis. The CB beam failed suddenly at the compression zone. Figure 15, shows the compression failure of the CB beam. The BSCP- 6 beam failed under shear compression. After the peak load, the loading decreased gradually, and the beam failed in a ductile manner. There was a wider spread of tensile damage between the loading points and the supports of the shear span. The tensile damage was more concentrated under the loading point. As the steel plate began to yield, the intensity of the tensile damage significantly increased. This was exhibited by more cracks appearing in the beam than the ones observed in the BCSP-10 and BCSP-15 beams at that stage, as shown in Figure 16. Thirdly, the type of failure observed in the BCSP-10 beam was characterized by the crushing of the concrete in the flexural compression zone. The resulting flexural compression failure occurred between the two loading plates, as shown in Figure 17. Finally, the BCSP-15 beam displayed more ductile behavior than the rest of the specimens. The BCSP-15 beam sustained the ultimate load for a longer time, with an increase in its deflection. The mid-span of the beam was its critical section. The maximum damage tension of the beam was concentrated in its mid-span. This is demonstrated by the micro-cracks displayed in the FE model, as shown in Figure 18.

Hence, the FE model has the ability to capture the locations and patterns of cracks, from the application of loading until the failure of a beam. The predictions made by the FE models were in line with the experimental observations. 


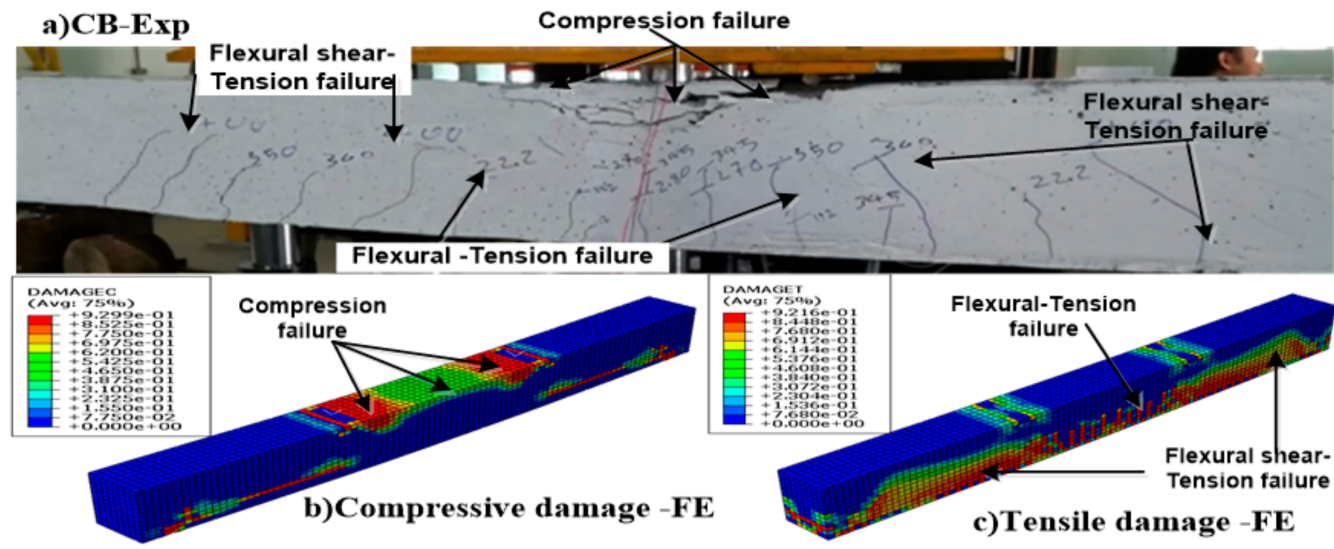

Figure 15. Comparison between (a) the experimental tests with the FE analysis of the (b) compressive and (c) tensile damage cracks in the $\mathrm{CB}$ at the point of failure.

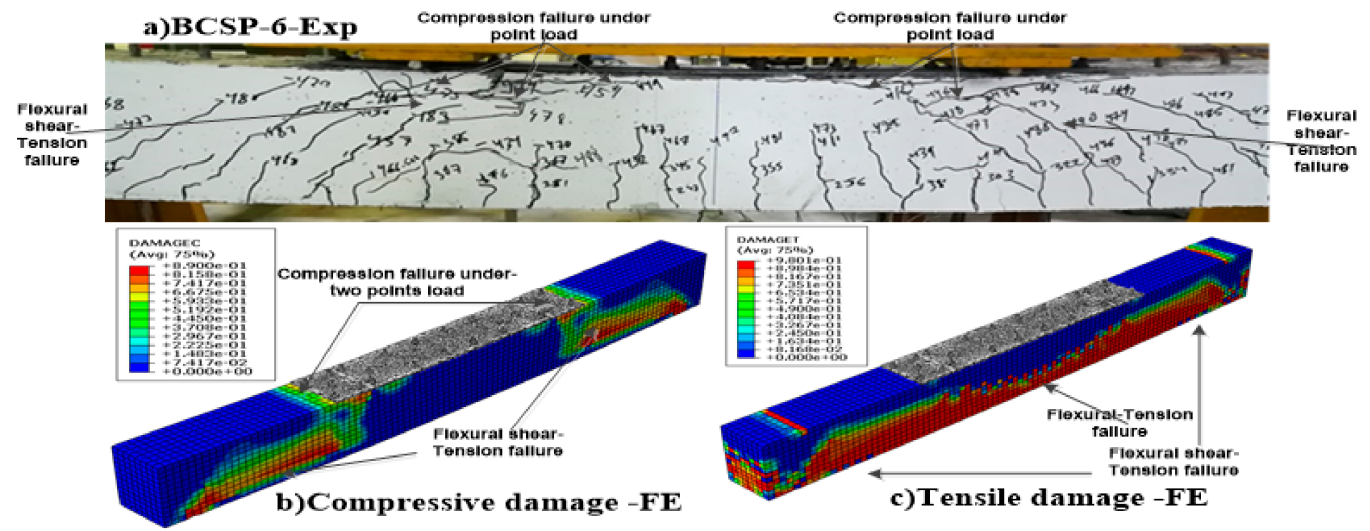

Figure 16. Comparison between (a) the experimental tests with the FE modelling of the (b) compressive and (c) tensile damage cracks in the BCSP-6 beam at the point of failure.

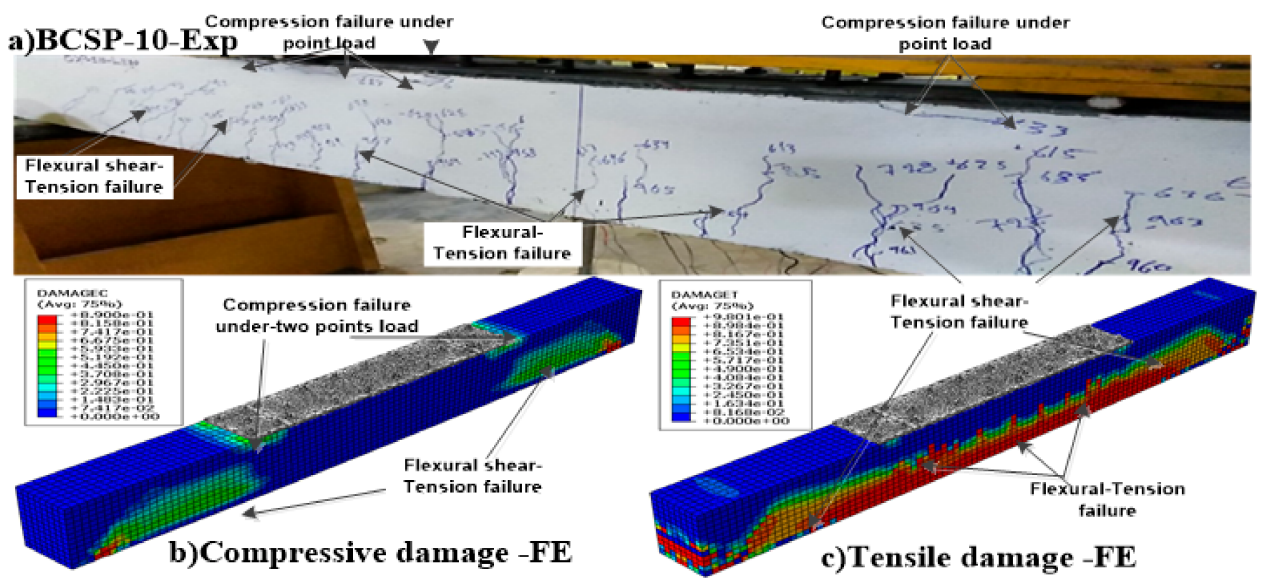

Figure 17. Comparison between (a) the experimental tests with the FE modelling of the (b) compressive and (c) tensile damage cracks in the BCSP-10 beam at the point of failure. 


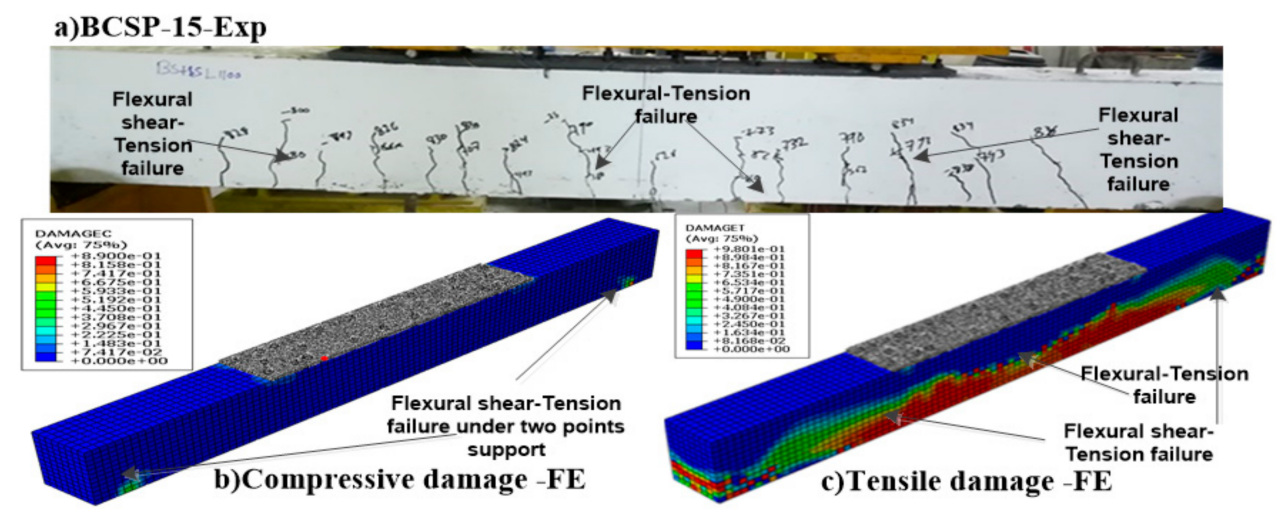

Figure 18. Comparison between (a) the experimental tests with the FE modelling of the (b) compressive and (c) tensile damage cracks in the BCSP-15 beam at the point of failure.

\section{Conclusions}

The behavior of over-reinforced concrete beams strengthened with bolt-compression steel plates (BCSPs) was investigated in this study. Based on a comparison of the experimental tests and the numerical results, the following conclusions can be drawn:

1. From the results of the experimental test, the load-carrying capacity and EA of the BCSP beams increased with the increase of the steel plate thickness in comparison with the control beam. The peak load-capacity of the BCSP beams ranged from $73.7 \%$ to $149 \%$ that of the CB. It was also observed that the increase in EA was about 247.5\%, 317.5\%, and 458.3\% for the beams with $6 \mathrm{~mm}$, $10 \mathrm{~mm}$, and $15 \mathrm{~mm}$ steel plate thicknesses, respectively.

2. Strengthening of over-reinforced concrete beams can be accomplished using steel plates. The BCSP system controls the spalling of the concrete cover at the compression section and increases the ductility, stiffness, and EA by improving the compressive strength. This implies that there is a change of failure mode, with steel yielding from the brittle failure of the $C B$ to the ductile failure of the BCSP beams, which depend on the thicknesses of the steel plates.

3. Generally, there was a mild increase in the member stiffness of the BCSP beams over the CB after cracking. The plates exerted higher reactions against downward displacement, preventing the BCSP beam section from failing.

4. Applying bolts to the steel plates increased the confinement of the arrangement prior to bonding. The plate increased the compressive strength of the beam. These phenomena influenced the mode of failure of the beams, and, as a result, there was a significant reduction in the amount of horizontal cracking. Hence, failure occurred more readily on the surface than at the compression zone. The BCSP-15 beam, which had the greatest plate thickness, also experienced the best confinement effect on the development of its failure mode, resulting in a failure load increase.

5. The concrete failure characteristics were satisfactorily and accurately predicted using the damaged plasticity model. The load transfer between the steel plate and concrete were simulated using the cohesive behavior method model. This displayed very satisfactory results.

6. Based on comparisons between the experimental and FE analysis of the curves' mid-span displacement under load, EA, and crack patterns with varying failure modes, it can be concluded that the proposed model is in accordance with the test results. Therefore, FE models used here can be used for further investigation.

7. The implication of these observations is that there is a potentially beneficial reduction of steel bars at the compression zone when using a bolt-compression steel plate for strengthening. This plate can yield a reduction in the cost of the overall materials used, as well as increase durability, since the same strength levels can be reached at a reduced area fraction when using the developed system. 
Author Contributions: Conceptualization, S.A., Z.I. and P.S.; Data curation, S.A.; Formal analysis, S.A.; Funding acquisition, S.A.; Investigation, S.A., Z.I. and P.S.; Methodology, S.A., Z.I. and P.S.; Project administration, S.A. Software, S.A., A.J. and K.N.; Supervision, Z.I. and P.S.; Validation, S.A.; Visualization, S.A., A.J. and K.N.; Writing-original draft, S.A.; Writing-review and editing, S.A., Z.I., P.S. and A.J. All authors have read and agreed to the published version of the manuscript.

Funding: This research received the funding no (project number: GPF015A-2018) by the Faculty Research Grant of the University of Malaya (UM).

Acknowledgments: The authors are interested in expressing their gratitude for the support provided by the University of Malaya (UM). The first author appreciates the Department of Civil Engineering, College of Engineering, Al-Mustansiriyiah University, and the Ministry of Higher Education of Iraq for providing support for her.

Conflicts of Interest: The authors declare no conflict of interest

\section{Nomenclature}

$a$

$A_{\mathcal{S}}$

$A_{p}$

b

h

$d$

$L_{p}$

$t_{p}$

$\mathrm{w}_{\mathrm{p}}$

$\mathrm{E}_{\mathrm{C}}$

$E_{p}$

$\mathrm{E}_{\mathrm{S}}$

$f c^{\prime}$

$f y$

$\mathrm{P}_{\text {spall }}$

$P_{\text {peak }}$

$\Delta_{\text {Ppeak }}$

$\Delta_{\text {spall }}$

$\Delta_{\text {cr }}$

$K_{\text {Pspall }}$

K Ppeak

$\mathrm{K}_{0.3 P p e a k}$

SP

CB

EA

$\mu_{1}$

$\mu_{2}$

$\varepsilon_{\mathrm{c}}$ Spall

$\varepsilon_{\mathrm{S} \text { Spall }}$

$\varepsilon_{\mathrm{c}}$ Peak

$\varepsilon_{\text {s Peak }}$

FEA

Exp

CDP

CSA

$\mathrm{ACI}$
Shear span length

Area of tensile longitudinal reinforcement, $\mathrm{mm}$

Area of steel plate, $\mathrm{mm}$

Width of the reinforced concrete cross section, $\mathrm{mm}$

Height of the reinforced concrete cross section, $\mathrm{mm}$

Effective depth of the reinforced concrete cross section, $\mathrm{mm}$

Length of steel plate, $\mathrm{mm}$

Thickness of steel plate

Width of steel plate

Modulus of elasticity for concrete, GPa

Modulus of elasticity of steel plate, GPa

Modulus of elasticity of tensile longitudinal reinforcement, GPa

Concrete compressive strength, $\mathrm{MPa}$

Steel yielding strength, $\mathrm{MPa}$

Spall loading, $\mathrm{kN}$

Peak loading, $\mathrm{kN}$

Displacement at peak loading, $\mathrm{mm}$

Displacement at spall loading, $\mathrm{mm}$

Displacement at first crack, $\mathrm{mm}$

Stiffness at spall loading, $\mathrm{kN} \cdot \mathrm{mm}$

Stiffness of peak loading, $\mathrm{kN} \cdot \mathrm{mm}$

Stiffness of $0.3 \%$ peak loading, $\mathrm{kN} \cdot \mathrm{mm}$

Steel plate

Control beam

Energy absorption, $\mathrm{kN} \cdot \mathrm{mm}$

Ductility $=\Delta_{\text {Peak }} / \Delta_{\text {spall }}$

Ductility $=\Delta_{0.9 \text { spall }} / \Delta_{\text {spall }}$

Strain of concrete at spall loading

Strain of steel reinforcement at spall loading

Strain of concrete at peak loading

Strain of steel reinforcement at peak loading

Finite Element Analysis

Expermental work

Damage Plasticity Model for Concrete

Canadian Standards Association

American Concrete Institute 


\section{References}

1. Swamy, R.; Jones, R.; Charif, A. The effect of external plate reinforcement on the strengthening of structurally damaged RC beams. Struct. Eng. 1989, 67, 45-56.

2. Jones, R.; Swamy, R.; Charif, A. Plate separation and anchorage of reinforced concrete beams strengthened by epoxy-bonded steel plates. Struct. Eng. 1988, 66, 85-94.

3. Jones, R.; Swamy, R.; Ang, T. Under-and over-reinforced concrete beams with glued steel plates. Int. J. Cem. Compos. Lightweight Concr. 1982, 4, 19-32. [CrossRef]

4. Thamrin, R.; Sari, R.P. Flexural capacity of strengthened reinforced concrete beams with web bonded steel plates. Procedia Eng. 2017, 171, 1129-1136. [CrossRef]

5. Oehlers, D.J.; Moran, J.P. Premature failure of externally plated reinforced concrete beams. J. Struct. Eng. 1990, 116, 978-995. [CrossRef]

6. Oehlers, D.; Ali, M.M.; Luo, W. Upgrading continuous reinforced concrete beams by gluing steel plates to their tension faces. J. Struct. Eng. 1998, 124, 224-232. [CrossRef]

7. Swamy, R.; Mukhopadhyaya, P.; Lynsdale, C. Strengthening for shear of RC beams by external plate bonding. Struct. Eng. 1999, 77, 19-30.

8. Nguyen, N.; Oehlers, D.; Bradford, M. An analytical model for reinforced concrete beams with bolted side plates accounting for longitudinal and transverse partial interaction. Int. J. Solids Struct. 2001, 38, 6985-6996. [CrossRef]

9. Zhu, Y.; Su, R.; Zhou, F. Seismic behavior of strengthened reinforced concrete coupling beams by bolted steel plates, Part 1: Experimental study. Struct. Eng. Mech. 2007, 27, 149-172. [CrossRef]

10. Su, R.; Li, L.; Lo, S. Longitudinal partial interaction in bolted side-plated reinforced concrete beams. Adv. Struct. Eng. 2014, 17, 921-936. [CrossRef]

11. Li, L.Z.; Wu, Z.L.; Yu, J.T.; Wang, X.; Zhang, J.X.; Lu, Z.D. Numerical simulation of the shear capacity of bolted side-plated RC beams. Eng. Struct. 2018, 171, 373-384. [CrossRef]

12. Shan, Z.; Su, R. Flexural capacity model for RC beams strengthened with bolted side-plates incorporating both partial longitudinal and transverse interactions. Eng. Struct. 2018, 168, 44-57. [CrossRef]

13. Martinez, S.; Nilson, A.H. Spirally Reinforced High- Strength Concrete Columns. ACT Struct. 1984, 81, 431-442.

14. Siu, W.; Su, R. Effects of plastic hinges on partial interaction behaviour of bolted side-plated beams. J. Constr. Steel Res. 2010, 66, 622-633. [CrossRef]

15. Li1a, L.-Z.; Jiang, C.-J. A piecewise linear transverse shear transfer model for bolted side-plated beams. Struct. Eng. Mech. 2017, 62. [CrossRef]

16. Base, G. Helical reinforcement in the compression zone of concrete beams. Constr. Eng. 1962, 57, 456-460.

17. Base, G. Effectiveness of helical binding in the compression zone of concrete beams. J. Proc. 1965, 62, 763-782.

18. Li, J.; Hadi, M. Behaviour of externally confined high-strength concrete columns under eccentric loading. Compos. Struct. 2003, 62, 145-153. [CrossRef]

19. Hadi, M.N. Behaviour of high strength axially loaded concrete columns confined with helices. Constr. Build. Mater. 2005, 19, 135-140. [CrossRef]

20. Hadi, M.N. Helically reinforced HSC beams reinforced with high strength steel. Int. J. Mater. Prod. Technol. 2005, 23, 138-148. [CrossRef]

21. Muhammad, N.S.; Hadi, N.E. Effects of tensile reinforcement ratio and compressive strength on the behaviour of over-reinforced helically confined HSC beams. Constr. Build. Mater. 2007, 21, 269-276.

22. Joo Kim, D.; Naaman, A.E.; El-Tawil, S. Comparative flexural behavior of four fiber reinforced cementitious composites. Cem. Concr. Compos. 2008, 30, 917-928. [CrossRef]

23. Delalibera, R.G.; Giongo, J.S. Theoretical and numerical analysis of reinforced concrete beams with confinement reinforcement. Rev. IBRACON Estrut. Mater. 2008, 1, 17-30. [CrossRef]

24. Øverli, J.A.; Jensen, T.M. Increasing ductility in heavily reinforced LWAC structures. Eng. Struct. 2014, 62, 11-22. [CrossRef]

25. Alasadi, S.S.; AlKafaji, J.M.; Kheder, G.F. Flexural Behavior of Hybrid Reinforced Concrete Beams, in Civil Engineering Department; Al-Mustansiriyah University Republic of Iraq; Ministry of Higher Education \& Scientific Research: City of Baghdad, Iraq, 2006. 
26. Qin, R.; Zhou, A.; Lau, D. Effect of reinforcement ratio on the flexural performance of hybrid FRP reinforced concrete beams. Compos. Part B Eng. 2017, 108, 200-209. [CrossRef]

27. Al-Osta, M.A.; Isa, M.N.; Baluch, M.H.; Rahman, M.K. Flexural behavior of reinforced concrete beams strengthened with ultra-high performance fiber reinforced concrete. Constr. Build. Mater. 2017, 134, $279-296$. [CrossRef]

28. Association, P.C. Notes on ACI 318-02: Building Code Requirements for Structural Concrete with Design Applications; Portland Cement Association: Skokie, IL, USA, 2002.

29. AS3600. Australian Standard for Concrete Structures; Standards Association of Australia: Sydney, Australia, 2001.

30. Simulia, D. ABAQUS 6.11 Analysis User's manual. Abaqus 6.11 Documentation; Abaqus: Johnston, RI, USA, 2011.

31. Tee, H.H.; Al-Sanjery, K.; Chiang, J.C.L. Behaviour of Over-reinforced Concrete Beams with Double Helix and Double Square Confinements Related to Ultimate Bending and Shear Strength. J. Phys. Sci. 2018, 29, 77-98.

32. Rassouli, B.; Shafaei, S.; Ayazi, A.; Farahbod, F. Experimental and numerical study on steel-concrete composite shear wall using light-weight concrete. J. Constr. Steel Res. 2016, 126, 117-128. [CrossRef]

33. Bickford, J. Handbook of bolts and bolted joints. CRC Press: New York, NY, USA, 1998.

34. Bsi, B. 8110-1: 1997, Structural Use of Concrete, Code of Practice for Design and Construction, Part 1; British Standard Institution: London, UK, 1997.

35. Standard, B. Structural Use of Concrete; BS8110; British Standard Institution: London, UK, 1986.

36. CSA. Design and Construction of Building Structures with Fibre-Reinforced Polymers; CSA: Mississauga, ON, Canada, 2012.

37. Al Zand, A.W.; Badaruzzaman, W.H.W.; Mutalib, A.A.; Hilo, S.J. The enhanced performance of CFST beams using different strengthening schemes involving unidirectional CFRP sheets: An experimental study. Eng. Struct. 2016, 128, 184-198. [CrossRef]

38. Arivalagan, K.; Kandasamy, K. Energy absorption capacity of composite beams. J. Eng. Sci. Technol. Rev. 2009, 2, 145-150. [CrossRef]

39. Mohammed, K.; Kareem, S.S. Deficient Reinforced Concrete Beam-Column Joint Strengthening. Pertanika J. Sch. Res. Rev. 2018, 4, 11-25.

40. Hanif, M.U.; Ibrahim, Z.; Ghaedi, K.; Hashim, H.; Javanmardi, A. Damage assessment of reinforced concrete structures using a model-based nonlinear approach-A comprehensive review. Constr. Build. Mater. 2018, 192, 846-865. [CrossRef]

41. Nie, J.G.; Hu, H.S.; Fan, J.S.; Tao, M.X.; Li, S.Y.; Liu, F.J. Experimental study on seismic behavior of high-strength concrete filled double-steel-plate composite walls. J. Constr. Steel Res. 2013, 88, 206-219. [CrossRef]

42. Hanif, M.U.; Ibrahim, Z.; Jameel, M.; Ghaedi, K.; Aslam, M. A new approach to estimate damage in concrete beams using non-linearity. Constr. Build. Mater. 2016, 124, 1081-1089. [CrossRef]

43. Lopez-Almansa, F.; Alfarah, B.; Oller, S. Numerical simulation of RC frame testing with damaged plasticity model. Comparison with simplified models. In Proceedings of the Second European Conference on Earthquake Engineering and Seismology, Istanbul, Turkey, 24-29 August 2014.

44. Lubliner, J.; Oliver, J.; Oller, S.; Oñate, E. A plastic-damage model for concrete. Int. J. Solids Struct. 1989, 25, 299-326. [CrossRef]

45. Javanmardi, A.; Ibrahim, Z.; Ghaedi, K.; Khan, N.B.; Ghadim, H.B. Seismic isolation retrofitting solution for an existing steel cable-stayed bridge. PLoS ONE 2018, 13, e0200482. [CrossRef]

46. Garg, A.K.; Abolmaali, A. Finite-element modeling and analysis of reinforced concrete box culverts. J. Transp. Eng. 2009, 135, 121-128. [CrossRef]

47. Drygala, I.J.; Dulinska, J.M. Full-Scale Experimental and Numerical Investigations on the Modal Parameters of a Single-Span Steel-Frame Footbridge. Symmetry 2019, 11, 404. [CrossRef]

48. Roudane, B.; Adanur, S.; Altunışık, A.C. Numerical Modeling of Masonry Infilled Reinforced Concrete Building during Construction Stages Using ABAQUS Software. Buildings 2019, 9, 181. [CrossRef]

49. Hanif, M.U.; Ibrahim, Z.; Ghaedi, K.; Javanmardi, A.; Rehman, S.K. Finite Element Simulation of Damage in RC Beams. J. Civ. Eng. Sci. Technol. 2018, 9, 50-57. [CrossRef]

(C) 2019 by the authors. Licensee MDPI, Basel, Switzerland. This article is an open access article distributed under the terms and conditions of the Creative Commons Attribution (CC BY) license (http://creativecommons.org/licenses/by/4.0/). 